\title{
Assay Conditions Influence Affinities of Rat Organic Cation Transporter 1: Analysis of Mutagenesis in the Modeled Outward-Facing Cleft by Measuring Effects of Substrates and Inhibitors on Initial Uptake ${ }^{\mathrm{S}}$
}

\author{
Valentin Gorboulev, Saba Rehman, Christoph M. Albert, Ursula Roth, Marleen J. Meyer, \\ Mladen V. Tzvetkov, Thomas D. Mueller, and Hermann Koepsell \\ Institute of Anatomy and Cell Biology, University of Würzburg, Würzburg, Germany (V.G.,S.R. C.M.A., U.R. H.K.); Institute of \\ Clinical Pharmacology, University Medical Center, Georg-August University, Göttingen, Germany (M.J.M., M.V.T.); Institute of \\ Pharmacology, Center of Drug Absorption and Transport, University Medical Center Greifswald, Greifswald, Germany (M.V.T.); \\ and Department of Molecular Plant Physiology and Biophysics, Julius-von-Sachs-Institute, University of Würzburg, Würzburg, \\ Germany (T.D.M., H.K.)
}

Received September 29, 2017; accepted January 12, 2018

\begin{abstract}
The effects of mutations in the modeled outward-open cleft of rat organic cation transporter 1 (rOCT1) on affinities of substrates and inhibitors were investigated. Human embryonic kidney 293 cells were stably transfected with rOCT1 or rOCT1 mutants, and uptake of the substrates 1-methyl-4-phenylpyridinium ${ }^{+}\left(\mathrm{MPP}^{+}\right)$and tetraethylammonium ${ }^{+}\left(\mathrm{TEA}^{+}\right)$or inhibition of $\mathrm{MPP}^{+}$uptake by the nontransported inhibitors tetrabutylammonium ${ }^{+}\left(\mathrm{TBuA}^{+}\right)$, tetrapentylammonium ${ }^{+}\left(\mathrm{TPeA}^{+}\right)$, and corticosterone was measured. Uptake measurements were performed on confluent cell layers using a 2-minute incubation or in dissociated cells using incubation times of 1,5 , or 10 seconds. With both methods, different apparent Michaelis-Menten constant $\left(K_{\mathrm{m}}\right)$ values, different $I_{50}$ values, and varying effects of mutations were determined. In addition, varying $\mathrm{IC}_{50}$ values for the inhibition of $\mathrm{MPP}^{+}$uptake
\end{abstract}

and varying effects of mutations were obtained when different $\mathrm{MPP}^{+}$concentrations far below the apparent $K_{\mathrm{m}}$ value were used for uptake measurements. Eleven mutations were investigated by measuring initial uptake in dissociated cells and employing $0.1 \mu \mathrm{M}$ $\mathrm{MPP}^{+}$for uptake during inhibition experiments. Altered affinities for substrates and/or inhibitors were observed when Phe160, Trp218, Arg440, Leu447, and Asp475 were mutated. The mutations resulted in changes of apparent $K_{\mathrm{m}}$ values for TEA ${ }^{+}$and/or $\mathrm{MPP}^{+}$. Mutation of Trp218 and Asp475 led to altered $\mathrm{IC}_{50}$ values for $\mathrm{TBuA}^{+}, \mathrm{TPeA}^{+}$, and corticosterone, whereas the mutation of Phe160 and Leu447 changed the $\mathrm{IC}_{50}$ values for two inhibitors. Thereby amino acids in the outward-facing conformation of rOCT1 could be identified that interact with structurally different inhibitors and probably also with different substrates.

\section{Introduction}

Organic cation transporters (OCTs) OCT1, OCT2, and OCT3 (SLC22A1-3) of the major facilitator superfamily MFS play pivotal roles in the absorption, excretion, and tissue distribution of many cationic drugs including psychopharmaca and cytostatics (Koepsell et al., 2007; Ahlin et al., 2008; Nies et al., 2011; Koepsell, 2013; Lin et al., 2015; Chen et al., 2017). The polyspecificity of OCTs explains their predominant role for drug bioavailability and the high probability for drugdrug interactions at the transporter level. The identification of drugs that are transported by OCTs or inhibit OCTs has

The work was supported by the Deutsche Forschungsgemeinschaft [SFB487/A4, KO 862/6-1].

https://doi.org/10.1124/mol.117.110767.

S This article has supplemental material available at molpharm. aspetjournals.org. become an important issue in pharmacology. For example, in vitro testing of human OCT1 (hOCT1) for drug-drug interactions was recommended in 2015 by the European Medicines Agency. Although methods to identify new substrates and inhibitors of OCTs have been established, so far no satisfying strategies for in silico and/or in vitro distinction between substrates and inhibitors and for elucidation of biomedically relevant effects of transporter polymorphisms have been found (Koepsell, 2015; Chen et al., 2017). The reasons are that the transport mechanisms of OCTs are not fully understood, no crystal structures are available, and our molecular understanding of cation binding and translocation based on mutagenesis is very limited.

Previously, we investigated the transport mechanisms of OCT1 and OCT2 expressed in oocytes of Xenopus laevis. We provided evidence that these transporters are polyspecific facilitated diffusion systems that can operate as electrogenic

ABBREVIATIONS: 3D, three-dimensional; ANOVA, analysis of variance; cRNA, complementary RNA; HEK, human embryonic kidney; hOCT, human organic cation transporter; $\mathrm{K}_{\mathrm{m}}$, Michaelis-Menten constant; MFS, major facilitator superfamily; $\mathrm{Mg}^{-\mathrm{Ca}-\mathrm{PBS}, 0.5 \mathrm{mM} \mathrm{MgCl}}$ and $1 \mathrm{mM}$ CaCl$_{2}$; MOPS, 4-morpholinepropanesulfonic acid; $\mathrm{MPP}^{+}$, 1-methyl-4-phenylpyridinium ${ }^{+}$; OCT, organic cation transporter; PBS, phosphate-buffered saline; rOCT, rat organic cation transporter; $\mathrm{TBuA}^{+}$, tetrabutylammonium ${ }^{+} ; \mathrm{TEA}^{+}$, tetraethylammonium ${ }^{+} ; \mathrm{TPeA}^{+}$, tetrapentylammonium ${ }^{+}$. 
uniporters or as electroneutral cation exchangers (Busch et al., 1996b; Arndt et al., 1998; Budiman et al., 2000; Volk et al., 2003; Koepsell, 2011). Studying structure-function relationships in rat OCT1 (rOCT1), we determined the effects of several single point mutations on affinities of substrates and inhibitors (Gorboulev et al., 1999, 2005; Popp et al., 2005; Volk et al., 2009). We interpreted these data with the help of homology models obtained using the crystal structure of bacterial Lac permease transporter, which belongs to the MFS superfamily (Pao et al., 1998; Abramson et al., 2003), as template. To determine the effects of mutations on the affinities of tetraethylammonium ${ }^{+}\left(\mathrm{TEA}^{+}\right)$and 1-methyl-4phenylpyridinium ${ }^{+}\left(\mathrm{MPP}^{+}\right)$uptake and on uptake inhibition by the nontransported inhibitors corticosterone and tetrabutylammonium $^{+}\left(\mathrm{TBuA}^{+}\right)$, rOCT1 mutants expressed in oocytes were characterized by measuring the uptake of radioactive substrates or substrate-induced inward currents. For inhibition studies, we measured the uptake of radioactive substrates using substrate concentrations below the apparent Michaelis-Menten constant $\left(K_{\mathrm{m}}\right)$ value and a 30 -minute incubation time or substrate-induced inward current using substrate concentrations above the apparent $K_{\mathrm{m}}$ value and a 45-second incubation time. For molecular interpretations, we made simplifying assumptions (e.g., that the effects of mutations in the modeled outward-open cleft on affinities of the inhibitors indicate inhibitor interactions with the mutated amino acids). We became concerned about whether interpretations that were based on uptake measured after a 30-minute incubation time hold true because these measurements are not supposed to represent a defined transport mode.

During recent years, increasing evidence has been obtained that indicates complex structure-function relationships in OCTs that allow direct and indirect interactions between structurally different substrates and/or inhibitors. Thus, OCTs contain low-affinity and high-affinity binding sites, and cation binding to these sites may lead to direct cation replacement and/or allosteric interactions (Gorbunov et al., 2008; Minuesa et al., 2009; Koepsell, 2011, 2015). Different affinities of inhibitors of hOCT1 and hOCT2 were determined when different substrates were used for the uptake measurement (Ahlin et al., 2011; Belzer et al., 2013; Thévenod et al., 2013). In addition, different affinities for the inhibition of hOCT2 were obtained when 2-minute uptake measurements were performed in confluent cells versus 1-second uptake measurements in dissociated cells (Thévenod et al., 2013).

In the present study, we show that mutations of individual amino acids in rOCT1 may have quite different effects on apparent $K_{\mathrm{m}}$ values of $\mathrm{MPP}^{+}$and $\mathrm{TEA}^{+}$uptake, and on half-maximal $\mathrm{IC}_{50}$ values of $\mathrm{MPP}^{+}$uptake when different experimental conditions are used in the uptake measurements. To identify amino acids that interact with the nontransported inhibitors $\mathrm{TBuA}^{+}$, corticosterone, and tetrapentylammonium ${ }^{+}\left(\mathrm{TPeA}^{+}\right)$, we analyzed the effects of various mutations of amino acids located in the outwardopen cleft of our three-dimensional (3D) homology model on $\mathrm{IC}_{50}$ values of uptake under trans-zero conditions. The measurements were performed in stably transfected, dissociated human embryonic kidney (HEK) 293 cells using a 1-, 5-, or 10-second incubation time and a fixed low $\mathrm{MPP}^{+}$concentration for uptake in inhibition studies. The obtained data suggest that five amino acids in the outward-open cleft interact with $\mathrm{TEA}^{+}$and/or $\mathrm{MPP}^{+}$and indicate that four of these interact with $\mathrm{TBuA}^{+}, \mathrm{TPeA}^{+}$, and/or corticosterone.

\section{Materials and Methods}

Materials. $\left[{ }^{3} \mathrm{H}\right] \mathrm{MPP}^{+} \quad(3.1 \mathrm{TBq} / \mathrm{mmol})$ and $\left[{ }^{14} \mathrm{C} \mathrm{TEA}^{+} \quad(1.9\right.$ $\mathrm{GBq} / \mathrm{mmol}$ ) were purchased from American Radiolabeled Chemicals (St. Louis, MO). All other chemicals were obtained as described previously (Arndt et al., 2001; Popp et al., 2005; Tzvetkov et al., 2012).

Cloning. For expression in oocytes and transfection of HEK293 cells, wild-type rOCT1 (Gründemann et al., 1994) and rOCT1 mutants (Popp et al., 2005; Volk et al., 2009) were cloned into various vectors. The single point mutations were generated by polymerase chain reaction applying the overlap extension method (Ho et al., 1989), and all mutations were verified by DNA sequencing. For expression in oocytes, wild-type rOCT1 and rOCT1 mutants were cloned into vector pRSSP (Busch et al., 1996b). For transfection of HEK293 cells, rOCT1 and mutants were cloned into EcoRV/NotI sites of vector pcDNA3.1 (Egenberger et al., 2012) or into EcoRV/HindIII sites of the vector pcDNA5.1 (Tzvetkov et al., 2012).

Expression of rOCT1 and rOCT1 Mutants in Oocytes of $X$. laevis. pRSSP plasmids were purified and linearized with MluI. m7G $\left(5^{\prime}\right) \mathrm{ppp}\left(5^{\prime}\right) \mathrm{G}$-capped complementary RNAs (cRNAs) were prepared, and the cRNA concentrations were estimated from ethidium bromidestained agarose gels (Gründemann and Koepsell, 1994). Stage V--VI oocytes of $X$. laevis were obtained by partial ovariectomy, follicle cells were removed by treatment with collagenase $\mathrm{A}$, and oocytes were stored in Ori buffer ( $5 \mathrm{mM}$ MOPS, $100 \mathrm{mM} \mathrm{NaCl}, 3 \mathrm{mM} \mathrm{KCl}, 2 \mathrm{mM}$ $\mathrm{CaCl}_{2}$, and $1 \mathrm{mM} \mathrm{MgCl} 2$ adjusted to $\mathrm{pH} 7.4$ using $\mathrm{NaOH}$ ) supplemented with $50 \mathrm{mg} / \mathrm{l}$ gentamycin. The oocytes were injected with $50 \mathrm{nl}$ of $\mathrm{H}_{2} \mathrm{O}$ containing $10 \mathrm{ng}$ of cRNA encoding the transporters. For transporter expression, the oocytes were incubated for 3 days at $16^{\circ} \mathrm{C}$ in Ori buffer containing $50 \mathrm{mg} / \mathrm{ml}$ gentamicin.

Measurement of MPP $^{+}$Uptake in Oocytes. Transporterexpressing oocytes or control oocytes without cRNA injection were incubated for 30 minutes at room temperature with Ori buffer containing varying concentrations of $\mathrm{TEA}^{+}$traced with $\left[{ }^{14} \mathrm{C}\right] \mathrm{TEA}^{+}$, with varying concentrations of $\mathrm{MPP}^{+}$traced with $\left[{ }^{3} \mathrm{H}\right] \mathrm{MPP}^{+}$, or 0.1 $\mu \mathrm{M} \mathrm{MPP}^{+}$traced with $\left[{ }^{3} \mathrm{H}\right] \mathrm{MPP}^{+}$plus varying concentrations of $\mathrm{TEA}^{+}$or with $\mathrm{TBuA}^{+}$. Oocytes were washed with ice-cold Ori buffer, solubilized with $5 \%$ SDS in water, and the radioactivity was analyzed by liquid scintillation counting. Correction for nonspecific uptake was performed by subtracting uptake rates measured in noninjected control oocytes from the same batch of oocytes.

Generation and Cultivation of Stably Transfected HEK Cells. HEK293 cells were transfected with vector pcDNA5.1 or pcDNA3.1 containing rOCT1 wild-type and rOCT1 mutants and selected for stably transfected cell lines as described previously (Busch et al., 1996a). Cell lines exhibiting the highest saturable $\mathrm{MPP}^{+}$uptake were used for further studies. The cells were cultivated at $37^{\circ} \mathrm{C}$ in Dulbecco's modified Eagle's medium containing $3.7 \mathrm{~g} / \mathrm{l}$ $\mathrm{NaHCO}_{3}, 1.0 \mathrm{~g} / \mathrm{l}$ D-glucose, $2 \mathrm{mM}$ L-glutamine, $10 \%$ heat-inactivated fetal calf serum, 100,000 U/l penicillin, $100 \mathrm{mg} / \mathrm{l}$ streptomycin, and 0.8 g/l G418 (Geneticin; Thermo Fisher Scientific). Cultivation was performed in a humidified atmosphere containing $5 \% \mathrm{CO}_{2}$.

Two-Minute Uptake Measurements of $\mathrm{MPP}^{+}$in Monolayers of HEK293 Cells at $37^{\circ} \mathrm{C}$. HEK293 cells, which were stably transfected with vector pcDNA5.1 containing wild-type rOCT1, the rOCT1 mutants Y222F, D475E, or hOCT1 were cultivated in six-well plates until reaching confluence. After washing two times with $137 \mathrm{mM}$ $\mathrm{NaC1}, 2.7 \mathrm{mM} \mathrm{KCl}, 8 \mathrm{mM} \mathrm{Na}{ }_{2} \mathrm{HPO} 4$, and $1.6 \mathrm{mM} \mathrm{KH}_{2} \mathrm{PO}_{4}, \mathrm{pH} 7.4$ [phosphate-buffered saline (PBS)] supplemented with $0.5 \mathrm{mM} \mathrm{MgCl}_{2}$ and $1 \mathrm{mM} \mathrm{CaCl}_{2}(\mathrm{Mg}-\mathrm{Ca}-\mathrm{PBS})\left(37^{\circ} \mathrm{C}\right)$, the monolayers were incubated for 2 minutes at $37^{\circ} \mathrm{C}$ with $\mathrm{Mg}$-Ca-PBS containing varying concentrations of $\mathrm{MPP}^{+}$traced with $\left[{ }^{3} \mathrm{H}\right] \mathrm{MPP}^{+}, \mathrm{TEA}^{+}$traced with $\left[{ }^{14} \mathrm{C}\right] \mathrm{TEA}^{+}$, or $0.1 \mu \mathrm{M} \mathrm{MPP}^{+}$traced with $\left[{ }^{3} \mathrm{H}\right] \mathrm{MPP}^{+}$plus varying concentrations of $\mathrm{TEA}^{+}, \mathrm{MPP}^{+}$, or $\mathrm{TBuA}^{+}$. Uptake was stopped by washing with icecold PBS, cells were solubilized with $0.2 \mathrm{ml}$ of $4 \mathrm{M}$ guanidine thiocyanate and analyzed for radioactivity.

Measurements of Initial Uptake Rates in Dissociated HEK293 Cells at $37^{\circ} \mathbf{C}$. HEK293 cells stably transfected with vector 
pcDNA3.1 containing rOCT1 or rOCT1 mutants were cultivated until confluence. The cells were washed twice with PBS and suspended in the same buffer by shaking at room temperature. The cells were collected by centrifugation (10 minutes, $1000 \mathrm{~g})$ and suspended $\left(10^{8}\right.$ cells $/ \mathrm{ml}$ ) at $37^{\circ} \mathrm{C}$ in $\mathrm{Mg}$-Ca-PBS. Initial uptake rates in HEK293 cells expressing wild-type rOCT1 and most mutants were measured after incubation for 1 second with radioactively traced $\mathrm{MPP}^{+}$or for 10 seconds with radioactively traced $\mathrm{TEA}^{+}$. In HEK293 cells expressing mutant rOCT1(D475E), which has a largely reduced transport activity compared with wild-type rOCT1 (Gorboulev et al., 1999), $\mathrm{MPP}^{+}$uptake was measured after 5 seconds of incubation with substrates. To measure the inhibition of $\mathrm{MPP}^{+}$uptake by $\mathrm{TEA}^{+}$, $\mathrm{TBuA}^{+}, \mathrm{TPeA}^{+}$, or corticosterone, the inhibitors were added together with $\mathrm{MPP}^{+}$. Using these incubation times, the measurements are supposed to represent trans-zero substrate uptake, and passive diffusion of $\mathrm{TPeA}^{+}$and corticosterone was supposed to be negligible. To perform the short-time uptake measurements, $90 \mu \mathrm{l}$ of HEK293 cell suspension was placed at the bottom of $2-\mathrm{ml}$ tubes and mixed by agitation in a water bath at $37^{\circ} \mathrm{C}$. The uptake measurements were performed tube by tube employing a switched-on vortexing device and a metronome providing a 1-s pulse. Ten microliters of Mg-Ca-PBS buffer containing $1 \mathrm{mg} / \mathrm{ml}$ albumin and the appropriate concentration of inhibitor and/or radioactive and nonradioactive substrate was placed on the inner wall of the tube about $0.5 \mathrm{~cm}$ above the surface of the cell suspension. Albumin was added to increase the adhesion of the radioactive solution to the reaction vessel. Uptake measurement was started by mixing the solutions. For uptake measurements, the tube was added to the vortexer and stopped by the addition of $1 \mathrm{ml}$ of ice-cold stop solution after 1,5 , or 10 seconds, as indicated by the metronome. The stop solution consisted of PBS containing $100 \mu \mathrm{M}$ quinine. After two centrifugation/washing steps with ice-cold stop solution, cell pellets were solubilized with $0.2 \mathrm{ml}$ of $4 \mathrm{M}$ guanidine thiocyanate. Two milliliters of scintillation liquid was added, and radioactivity was determined by liquid scintillation counting.

Statistics and Fitting Procedures. For uptake measurements of $\left[{ }^{3} \mathrm{H}\right] \mathrm{MPP}^{+}$or $\left[{ }^{14} \mathrm{C}\right] \mathrm{TEA}^{+}$into oocytes, at least three different experiments employing different batches of oocytes were used. In each experiment, 8-10 oocytes were analyzed per experimental condition. For the determination of uptake rates of $\mathrm{MPP}^{+}$or $\mathrm{TEA}^{+}$ into HEK293 cells, at least three different experiments were performed. In each experiment, four individual measurements were performed per experimental condition. The software package GraphPad Prism version 4.1 (GraphPad Software, San Diego, CA) was used to compute statistical parameters. Apparent $K_{\mathrm{m}}$ values were determined by fitting the Michaelis-Menten equation (Fig. 1A; Table 1) or the Hill equation (Figs. 2-4; Tables 2 and 3) to substrate activation measurements. The data are presented as the replacement of radioactive substrate by nonlabeled substrate to avoid large scatter at high substrate concentrations. The equations used are indicated in Supplemental Fig. 1. In wild-type rOCT1 and most mutants, the obtained Hill coefficient was not statistically significantly different from one, and similar apparent $K_{\mathrm{m}}$ values were determined using the Michaelis-Menten or Hill equation. Attempts to fit the two-site competition model indicated in Supplemental Fig. 1 to the substrate replacement curves did not resolve two sites and did not improve the goodness of the fit. Half-maximal concentration values for the inhibition of $\left[{ }^{3} \mathrm{H}\right] \mathrm{MPP}^{+}$transport $\left(\mathrm{IC}_{50}\right)$ by substrates and nontransported inhibitors were determined by fitting the Hill equation to the data after subtracting uptake that could not be inhibited by the highest concentration of the respective compound that was used (see equation in Supplemental Fig. 1). Fitting the two-site competition model shown in Supplemental Fig. 1 to the inhibition data did not resolve two inhibitory sites. The presented apparent $K_{\mathrm{m}}$ values and $\mathrm{IC}_{50}$ values, which were obtained by fitting data from individual experiments, are the mean \pm S.D. The curves indicated in Figs. $2-7$ were obtained by fitting the Hill equation to data from the compiled experiments. In the graphs presented, individual data points are presented as mean \pm S.D. values from three or four individual
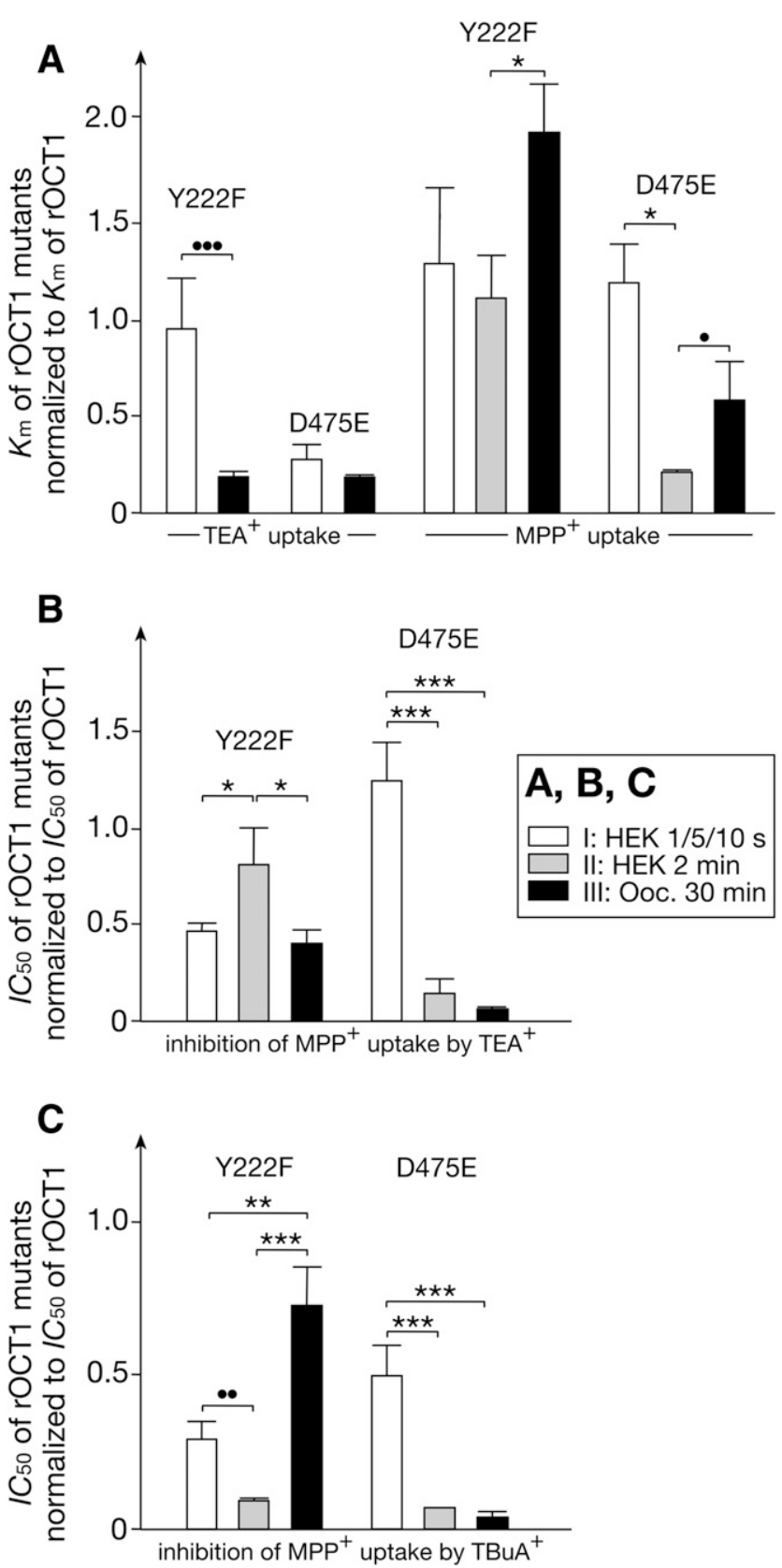

Fig. 1. Experimental conditions influence the effects of mutations in rOCT1 on the affinities of substrates and inhibitors. Apparent $K_{\mathrm{m}}$ values for $\mathrm{TEA}^{+}$ and $\mathrm{MPP}^{+}$uptake (A), and $\mathrm{IC}_{50}$ values for the inhibition of $\mathrm{MPP}^{+}$uptake by $\mathrm{TEA}^{+}(\mathrm{B})$ or by $\mathrm{TBuA}^{+}(\mathrm{C})$ mediated by rOCT1 wild-type and two rOCT1 mutants were determined using different experimental conditions, as described in Table 1. I, Initial uptake of $\mathrm{MPP}^{+}$or $\mathrm{TEA}^{+}$was measured in dissociated HEK293 cells (white bars). Incubation times of 1 second (MPP uptake by rOCT1 and mutant Y222F), 5 seconds $\left(\mathrm{MPP}^{+}\right.$uptake by mutant $\mathrm{D} 475 \mathrm{E})$, or 10 seconds (TEA ${ }^{+}$uptake) were used. II, Uptake of $\mathrm{MPP}^{+}$was measured in monolayers of HEK293 cells using an incubation time of 2 minutes, shown in gray bars. III, Uptake of $\mathrm{MPP}^{+}$was measured in oocytes using an incubation time of 30 minutes, shown in black bars. The apparent $K_{\mathrm{m}}$ values and $\mathrm{IC}_{50}$ values determined for the mutants presented in Table 1 were normalized to the respective mean values determined for rOCT1 wildtype. Mean \pm S.D. values of three or more experiments (Table 1) are indicated. $* P<0.05 ; * * P<0.01 ; * * * P<0.001$, significance of difference determined by ANOVA with post hoc Tukey test; $\bullet P<0.05$; $\bullet P<0.01$; $\bullet \bullet P<0.001$, significance of difference determined by Student's $t$ test.

experiments. When more than two groups were compared, the statistical significance of differences was determined by analysis of variance (ANOVA) using a post hoc Tukey comparison. The Student's $t$ test was 
TABLE 1

Comparison of apparent $K_{\mathrm{m}}$ values and $\mathrm{IC}_{50}$ values of rOCT1 wild-type and two rOCT1 mutants determined under different experimental conditions

Apparent $K_{\mathrm{m}}$ values of $\mathrm{TEA}^{+}$and $\mathrm{MPP}^{+}$uptake and $\mathrm{IC}_{50}$ values for the inhibition of uptake of $0.1 \mu \mathrm{M} \mathrm{MPP}^{+}$by $\mathrm{TEA}^{+}$or TBuA ${ }^{+}$mediated by rOCT1, rOCT1(Y222F), and rOCT1(D475E) were determined. The measurements were performed with stably transfected HEK293 cells (I, II) or with oocytes in which the transporters were expressed (III). I, Tracer uptake was measured in dissociated HEK293 cells at $37^{\circ} \mathrm{C}$ after incubation for 1 second $\left[\mathrm{MPP}^{+}\right.$uptake in rOCT1 and rOCT1(Y222F)], 5 seconds [MPP ${ }^{+}$uptake in rOCT1(D475E)], or 10 seconds (TEA ${ }^{+}$uptake). In Figs. 3-5 and Supplemental Fig. 4, the compiled uptake measurements are shown. II, Tracer uptake was measured in monolayers of HEK293 cells at $37^{\circ} \mathrm{C}$ after incubation for 2 min. The uptake measurements are shown in Supplemental Figs. 2 and 3. III, Tracer uptake was measured in oocytes expressing rOCT1 or rOCT1 mutants after 30-min incubation at room temperature. These data are taken from our previous publications (Gorboulev et al., 1999, 2005; Popp et al., 2005). The apparent $K_{\mathrm{m}}$ values were calculated by fitting the Michaelis-Menten equation to the data, whereas $\mathrm{IC}_{50}$ values were calculated by fitting the Hill equation to the data. Values are given as the mean \pm S.D. values; the numbers of experiments are indicated in parenthesis.

\begin{tabular}{|c|c|c|c|c|c|}
\hline & rOCT1 & TEA $^{+}$App. $K_{\mathrm{m}}$ & $\mathrm{MPP}^{+}$App. $K_{\mathrm{m}}$ & $\mathrm{TEA}^{+} \mathrm{IC}_{50}$ & $\mathrm{TBuA}^{+} \mathrm{IC}_{50}$ \\
\hline & & & & $\mu \mathrm{M}$ & \\
\hline I: HEK 1-s uptake & WT & $62 \pm 7.6(4)$ & $3.9 \pm 0.5$ & $42 \pm 7.1$ & $0.970 .22(4)$ \\
\hline II: HEK 2-min uptake & WT & $384 \pm 120(3)^{* * *}$ & $78 \pm 9.8(3)^{* * *}$ & $639 \pm 40(3)^{* * * *}$ & $8.0 \pm 1.8(3)^{* * *}$ \\
\hline III: Ooc. 30 -min uptake & WT & $75 \pm 11(8) \# \# \#$ & $4.9 \pm 1.4(4) \# \# \#$ & $132 \pm 21(6)^{* * *}, \# \# \#$ & $8.2 \pm 1.8(3)^{* * *}$ \\
\hline I: HEK 1-s uptake & $\mathrm{Y} 222 \mathrm{~F}$ & $59 \pm 15(4)$ & $5.1 \pm 1.7(3)$ & $20 \pm 1.5$ & $0.28 \pm 0.06(3)$ \\
\hline II: HEK 2-min uptake & $\mathrm{Y} 222 \mathrm{~F}$ & & $87 \pm 16(3) * * *$ & $526 \pm 132(3) * * *$ & $0.70 \pm 0.08$ \\
\hline III: Ooc. 30 -min uptake & $\mathrm{Y} 222 \mathrm{~F}$ & $21 \pm 1.5(4) \bullet \bullet \bullet$ & $9.0 \pm 0.7(3) \bullet, \# \# \#$ & $54 \pm 9.4(3) \bullet \bullet, \# \# \#$ & $6.0 \pm 1.1(3)^{* * *}, \# \# \#$ \\
\hline I: HEK 5-s uptake & $\mathrm{D} 475 \mathrm{E}$ & $18 \pm 5.0(4)$ & $4.8 \pm 0.9$ & $53 \pm 8.1(4)$ & $0.49 \pm 0.10$ \\
\hline II: HEK 2-min uptake & $\mathrm{D} 475 \mathrm{E}$ & & $21 \pm 2.1(3)^{* * *}$ & $81 \pm 17(3) *$ & $0.50 \pm 0.08$ \\
\hline III: Ooc. 30 -min uptake & $\mathrm{D} 475 \mathrm{E}$ & $18 \pm 1.0(3)$ & $3.1 \pm 0.9$ (3)\#\#\# & $8.1 \pm 1.2(3)^{* *}, \# \# \#$ & $0.32 \pm 0.15$ \\
\hline
\end{tabular}

App., apparent; Ooc., oocytes; WT, wild-type.

$* P<0.05 ; * * P<0.01 ; * * * P<0.001$ difference to experimental condition I measured by ANOVA and post hoc Tukey test; $\bullet P<0.05 ; \bullet \bullet P<0.01 ;$

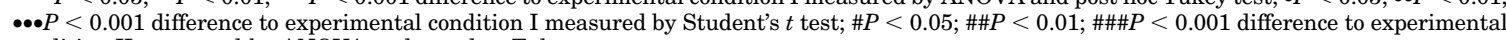
condition II measured by ANOVA and post hoc Tukey test.

used for the evaluation of statistical significance of difference between two groups. $P<0.05$ was considered statistically significant.

\section{Results}

Impact of Experimental Conditions on Affinities of rOCT1 for Substrates and Inhibitors and on Effects of Mutations on Affinities. Largely different apparent $K_{\mathrm{m}}$ values and $\mathrm{IC}_{50}$ values for substrates and inhibitors of OCT1 were determined in various laboratories using different expression systems and/or different experimental conditions for transport measurements (Koepsell et al., 2007; Nies et al., 2011). In different expression systems, such as $X$. laevis oocytes and epithelial cells, transporters may exist in diverging regulatory states. Using different incubation times for tracer uptake measurements may determine whether transzero cation import or net uptake of cation import minus cation export is analyzed. Tracer uptake in epithelial cells and cation-induced inward currents in voltage-clamped oocytes may record transport activity at different membrane potentials. When testing inhibitor affinities using different substrates, it turned out that the substrate properties may influence the $\mathrm{IC}_{50}$ values (Ahlin et al., 2011; Belzer et al., 2013; Thévenod et al., 2013). Previously, we characterized functional activities of wild-type rOCT1 and rOCT1 mutants expressed in oocytes of $X$. laevis by measuring tracer flux uptake after a 30-minute incubation at room temperature (Gorboulev et al., 1999; Popp et al., 2005) and by measuring cation-induced inward currents in voltage-clamped oocytes (Volk et al., 2009). We also measured the effects of a few mutations on initial rates of tracer flux at $37^{\circ} \mathrm{C}$ in stably transfected HEK293 cells (Egenberger et al., 2012). In other laboratories, functional analysis of hOCT1 was performed in stably transfected HEK293 cells by measuring tracer flux uptake in confluent cells using incubation times of several minutes duration (Nies et al., 2009; Chen et al., 2010; Tzvetkov et al., 2012; Matthaei et al., 2016).
In the present study, we compared apparent $K_{\mathrm{m}}$ values and $\mathrm{IC}_{50}$ values of wild-type rOCT1 as well as variants rOCT1 (Y222F) and rOCT1(D475E) in HEK293 cells and oocytes using different conditions for the uptake measurements. We measured apparent $K_{\mathrm{m}}$ values for the uptake of $\mathrm{TEA}^{+}$and $\mathrm{MPP}^{+}$, and $\mathrm{IC}_{50}$ values for inhibition of uptake of $0.1 \mu \mathrm{M}$ $\mathrm{MPP}^{+}$by $\mathrm{TEA}^{+}$or $\mathrm{TBuA}^{+}$. Apparent $K_{\mathrm{m}}$ values and $\mathrm{IC}_{50}$ values of wild-type rOCT1 and the two rOCT1 mutants are presented in Table 1 , and the effects of the mutations on apparent $K_{\mathrm{m}}$ values and $\mathrm{IC}_{50}$ values are shown in Fig. 1 . Uptake was determined at $37^{\circ} \mathrm{C}$ in stably transfected HEK293 cells or at room temperature in oocytes. We analyzed initial uptake rates in dissociated HEK293 cells or uptake after a 2-minute incubation in confluent cell layers of HEK293 cells. For measurements of initial uptake rates, incubation times of 1 second $\left[\mathrm{MPP}^{+}\right.$uptake by wild-type rOCT1 and rOCT1 $(\mathrm{Y} 222 \mathrm{~F})], 5$ seconds $\left(\mathrm{MPP}^{+}\right.$uptake by $\operatorname{rOCT} 1(\mathrm{D} 475 \mathrm{E})$ ), and 10 seconds $\left(\mathrm{TEA}^{+}\right.$uptake) were used. In oocytes, the transporter was expressed by cRNA injection, and the uptake of radioactive $\mathrm{MPP}^{+}$was measured after a 30-minute incubation.

For wild-type rOCT1, similar apparent $K_{\mathrm{m}}$ values for TEA ${ }^{+}$ or $\mathrm{MPP}^{+}$were determined in dissociated HEK293 cells and in oocytes, whereas the apparent $K_{\mathrm{m}}$ values measured in confluent HEK293 cells were 5-fold to 6-fold $\left(\mathrm{TEA}^{+}\right.$uptake) or 16-fold to 20 -fold ( $\mathrm{MPP}^{+}$uptake) higher (Table 1). The $\mathrm{IC}_{50}$ value for the inhibition of rOCT1-mediated uptake of $0.1 \mu \mathrm{M}$ $\mathrm{MPP}^{+}$by TEA ${ }^{+}$measured in confluent HEK293 cells was 15 times higher than in dissociated HEK293 cells and 5 times higher than in oocytes (Table 1). For inhibition of rOCT1mediated uptake of $0.1 \mu \mathrm{M} \mathrm{MPP}^{+}$by $\mathrm{TBuA}^{+}$, an approximately eight times lower $\mathrm{IC}_{50}$ value was determined in dissociated HEK293 cells compared with confluent HEK293 cells or compared with oocytes (Table 1).

It is noteworthy that we observed that the experimental conditions used for uptake measurements also influenced the determined functional effects of the mutations. In mutant 
$\circ 0.25 \mathrm{nM} \mathrm{MPP}^{+}$-12.5nM MPP ${ }^{+} \cdot 100 \mathrm{nM} \mathrm{MPP}^{+}$
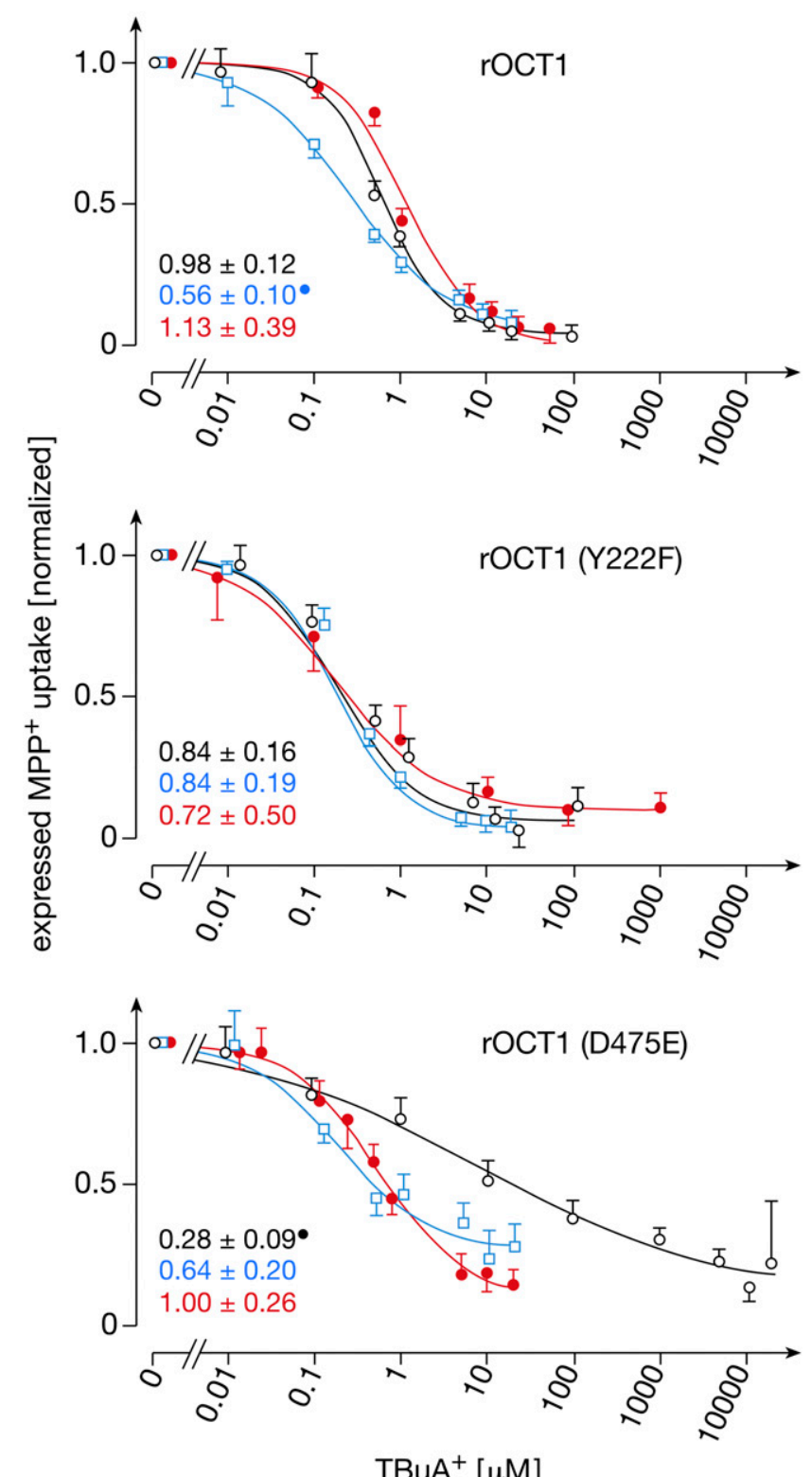

Fig. 2. Inhibition of $\mathrm{MPP}^{+}$uptake mediated by wild-type rOCT1, rOCT1 (Y222F), or rOCT1(D475E) by $\mathrm{TBuA}^{+}$measured at three different $\mathrm{MPP}^{+}$ concentrations far below the apparent $K_{\mathrm{m}}$ values for MPP ${ }^{+}$. In HEK293 cells stably transfected with the rOCT1, rOCT1(Y222F) or rOCT1(D475E) initial uptake measurements of $0.25,12.5$, or $100 \mathrm{nM} \mathrm{MPP}^{+}$in the presence of different concentrations of $\mathrm{TBuA}^{+}$were performed. Mean \pm S.D. values of three independent experiments are indicated. The data were normalized to $\mathrm{MPP}^{+}$uptake in the absence of $\mathrm{TBuA}^{+}$. The curves were obtained by fitting the Hill equation to the data. Mean \pm S.D. values of Hill coefficients are indicated that were determined by fitting the Hill equation to individual experiments. $\bullet P<0.05$ for difference to the Hill coefficient obtained for $\mathrm{TBuA}^{+}$inhibition measured with $100 \mathrm{nM} \mathrm{MPP}^{+}$determined by Student's $t$ test.

Y222F, the apparent $K_{\mathrm{m}}$ value for $\mathrm{TEA}^{+}$uptake measured in dissociated HEK293 cells was similar to that in wild-type rOCT1, whereas it was strongly decreased when uptake was measured in oocytes (Fig. 1A, left panel). Replacement of Asp475 by glutamate (mutant D475E) led to a similar strong decrease of the apparent $K_{\mathrm{m}}$ value for $\mathrm{TEA}^{+}$uptake determined in dissociated HEK293 cells and oocytes (Fig. 1A, left panel). The Y222F mutation did not alter the apparent $K_{\mathrm{m}}$ value for $\mathrm{MPP}^{+}$measured in dissociated or confluent HEK293 cells but induced an increase in apparent $K_{\mathrm{m}}$ values in oocytes (Fig. 1A, right panel). In the D475E mutant, compared with wild-type the apparent $K_{\mathrm{m}}$ value for $\mathrm{MPP}^{+}$uptake was not changed in dissociated HEK293 cells whereas it was decreased by different degrees in confluent HEK293 cells and oocytes (Fig. 1A, right panel). In mutant $\mathrm{Y} 222 \mathrm{~F}$, the $\mathrm{IC}_{50}$ value for the inhibition of $\mathrm{MPP}^{+}$uptake by $\mathrm{TEA}^{+}$was decreased compared with wild-type rOCT1 in dissociated HEK293 cells and oocytes, whereas it was not changed in confluent HEK293 cells (Fig. 1B, left panel). At variance, upon exchange of Asp475 with glutamate, the $\mathrm{IC}_{50}$ value for the inhibition of $\mathrm{MPP}^{+}$uptake by TEA ${ }^{+}$was not changed when analyzed in dissociated HEK293 cells, whereas it was strongly decreased when determined in confluent HEK293 cells and oocytes (Fig. $1 \mathrm{~B}$, right panel). Because of the $\mathrm{Y} 222 \mathrm{~F}$ mutation, the $\mathrm{IC}_{50}$ value for inhibition of $\mathrm{MPP}^{+}$uptake by $\mathrm{TBuA}^{+}$was decreased to different degrees in dissociated and confluent HEK293 cells but was not changed in oocytes (Fig. 1C, left panel). Upon replacement of Asp475 by glutamate, the $\mathrm{IC}_{50}$ value for the inhibition of $\mathrm{MPP}^{+}$uptake by $\mathrm{TBuA}^{+}$was halved in dissociated HEK293 cells and decreased by more than $90 \%$ in confluent HEK293 cells and oocytes (Fig. 1C, right panel).

Influence of the Substrate Concentration on the $\mathbf{I C}_{50}$ Values of Inhibitors. Since rOCT1 contains high- and lowaffinity cation binding sites (Gorbunov et al., 2008), we asked whether the inhibitors may inhibit cation transport with different affinities when different substrate concentrations far below their respective apparent $K_{\mathrm{m}}$ value are used for uptake measurements. In HEK293 cells stably transfected with rOCT1, rOCT1(Y222F), or rOCT1(D475E), we therefore measured the inhibition of 1-second uptake [rOCT1, rOCT1 (Y222F)] or 5-second uptake [rOCT1(D475E)] of $0.25 \mathrm{nM}$ $\mathrm{MPP}^{+}, 12.5 \mathrm{nM} \mathrm{MPP}^{+}$, or $0.1 \mu \mathrm{M} \mathrm{MPP}^{+}$by various concentrations of $\mathrm{TBuA}^{+}$and calculated the $\mathrm{IC}_{50}$ values by fitting the Hill equation to the data (Fig. 2; Table 2). Employing the three different $\mathrm{MPP}^{+}$concentrations, three different $\mathrm{IC}_{50}$ values were obtained for rOCT1 and $\mathrm{rOCT} 1(\mathrm{D} 475 \mathrm{E})$, whereas the $\mathrm{IC}_{50}$ values determined for $\operatorname{rOCT} 1(\mathrm{Y} 222 \mathrm{~F})$ were similar at all three $\mathrm{MPP}^{+}$concentrations. Interestingly the $\mathrm{IC}_{50}$ values determined for rOCT1 and $\mathrm{rOCT} 1(\mathrm{D} 475 \mathrm{E})$ using $12.5 \mathrm{nM}$ $\mathrm{MPP}^{+}$were lower compared with the values determined with $0.1 \mu \mathrm{M} \mathrm{MPP}^{+}$or $0.25 \mathrm{nM} \mathrm{MPP}^{+}$. Under most conditions a Hill coefficient around 1 was determined; however, Hill coefficients lower than 1 were obtained for inhibition of the uptake of $12.5 \mathrm{nM} \mathrm{MPP}^{+}$by wild-type rOCT1 and for inhibition of the uptake of $0.25 \mathrm{nM} \mathrm{MPP}^{+}$by rOCT1(D475E) (Fig. 2). Assuming that the effects of the different $\mathrm{MPP}^{+}$concentrations (all of which are far below the apparent $K_{\mathrm{m}}$ value of $\mathrm{MPP}^{+}$) are due to different interactions with high-affinity $\mathrm{MPP}^{+}$binding sites, the data suggest that interactions with two high-affinity $\mathrm{MPP}^{+}$binding sites are involved. The negative cooperativity observed under some conditions suggests that $\mathrm{TBuA}^{+}$binds to two binding sites that interact under the respective conditions. Using different $\mathrm{MPP}^{+}$concentrations for the uptake measurements, we also observed different effects of mutations on the efficacy of $\mathrm{TBuA}^{+}$inhibition. The mutation Y222F decreased the $\mathrm{IC}_{50}$ value for $\mathrm{TBuA}^{+}$inhibition of uptake of 0.1 $\mu \mathrm{M} \mathrm{MPP}^{+}$compared with wild-type rOCT1, but did not alter the $\mathrm{IC}_{50}$ value for $\mathrm{TBuA}^{+}$inhibition of the uptake of $12.5 \mathrm{nM}$ $\mathrm{MPP}^{+}$or $0.25 \mathrm{nM} \mathrm{MPP}{ }^{+}$(Table 2). On the other hand, the 


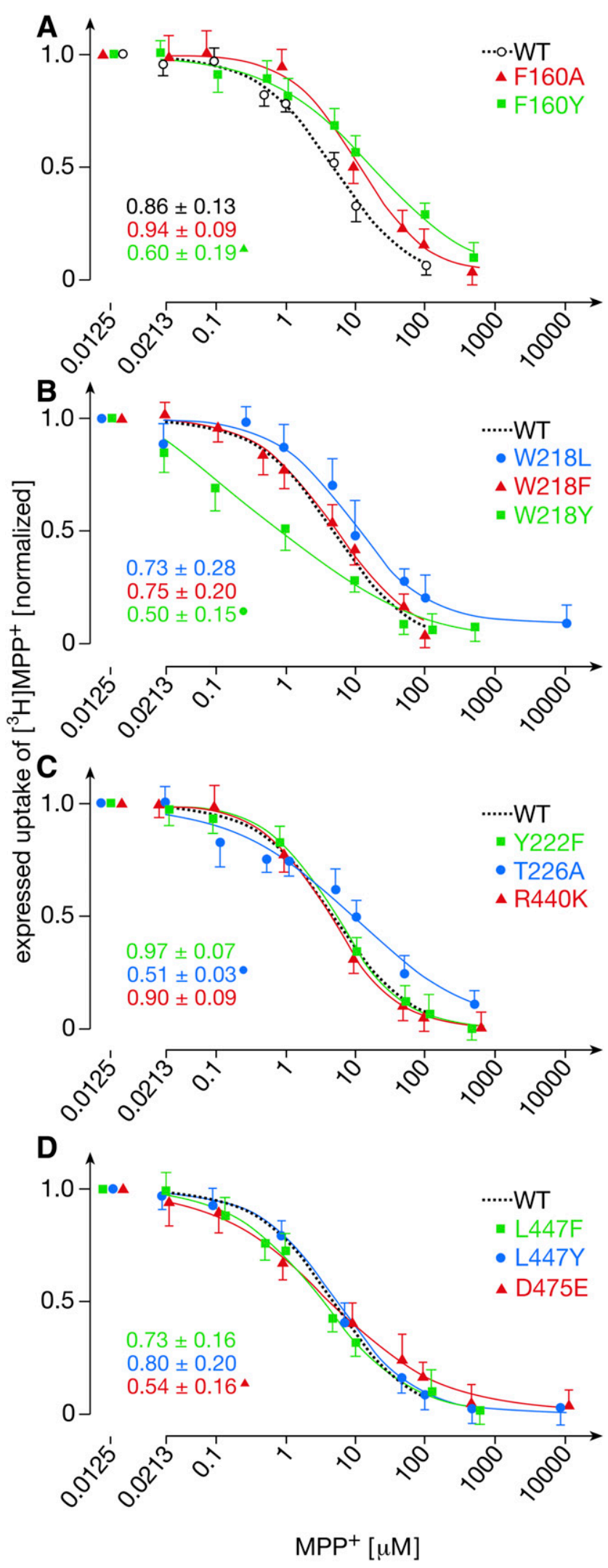

Fig. 3. Substrate dependence of initial rates of $\mathrm{MPP}^{+}$uptake mediated by wild-type rOCT1 and rOCT1 mutants expressed in HEK293 cells. (A) Effects of mutations of Phe160. (B) Effects of mutations of Trp218. (C) Effects of mutations of Tyr222, Thr226, and Arg440. (D) Effects of mutations of Leu447 and Asp475. In stably transfected HEK293 cells, the initial uptake rates of $12.5 \mathrm{nM} \mathrm{MPP}{ }^{+}$traced with $\left[{ }^{3} \mathrm{H}\right] \mathrm{MPP}^{+}$were mutation $\mathrm{D} 475 \mathrm{E}$ decreased the $\mathrm{IC}_{50}$ value for $\mathrm{TBuA}^{+}$inhibition of the uptake of $0.1 \mu \mathrm{M}$ and $12.5 \mathrm{nM} \mathrm{MPP}^{+}$, but increased the $\mathrm{IC}_{50}$ for $\mathrm{TBuA}^{+}$inhibition of the uptake of 0.25 $\mathrm{nM} \mathrm{MPP}^{+}$.

Effects of Mutations in rOCT1 on Apparent $K_{m}$ Values for $\mathrm{MPP}^{+}$and $\mathrm{TEA}^{+}$Determined from Initial Uptake Rates in Transfected HEK293 Cells. Measuring the inhibition of $\mathrm{TEA}^{+}$-induced currents by corticosterone in oocytes expressing rOCT1 mutants, we previously identified five amino acids (Phe160, Trp218, Arg440, Leu447, and Asp475) that are located in the outward-open cleft of our 3D structural model and influence the efficacy of corticosterone for the inhibition of $\mathrm{TEA}^{+}$uptake (Volk et al., 2009). Performing 30-minute uptake measurements of $\mathrm{TEA}^{+}$and $\mathrm{MPP}^{+}$in oocytes expressing wild-type rOCT1 and mutants $\mathrm{W} 218 \mathrm{~F}$ and D475E, we observed that replacement of Asp475 by glutamate changed the apparent $K_{\mathrm{m}}$ for $\mathrm{TEA}^{+}$uptake whereas the replacement of Trp218 by phenylalanine did not alter the apparent $K_{\mathrm{m}}$ values for $\mathrm{TEA}^{+}$and $\mathrm{MPP}^{+}$(Gorboulev et al., 1999; Popp et al., 2005). To study the functional significance of Phe160, Trp218, Arg440, Leu447, and Asp475 in the outwardfacing cleft of our 3D structural model under optimal experimental conditions, we analyzed mutants F160A, F160Y, W218L, W218F, W218Y, R440K, L447F, L447Y, and D475E on trans-zero uniport transport activity by measuring the initial uptake rates of $\mathrm{MPP}^{+}$and $\mathrm{TEA}^{+}$in dissociated, stably transfected HEK293 cells. Replacements of Phe160 by tyrosine or alanine; of Trp218 by phenylalanine, tyrosine, or leucine; and of Leu447 by phenylalanine or tyrosine were performed to determine effects of slightly and distinctly different structural changes. We also investigated the effects of mutations $\mathrm{Y} 222 \mathrm{~F}$ and T226A because uptake measurements in oocytes revealed effects on apparent $K_{\mathrm{m}}$ values for $\mathrm{TEA}^{+}$and/or $\mathrm{MPP}^{+}$by these mutations, although in our 3D structural models these amino acids were only found accessible in the inward-open cleft (Popp et al., 2005; Volk et al., 2009).

In HEK293 cells, the apparent $K_{\mathrm{m}}$ value for $\mathrm{MPP}^{+}$determined by fitting the Hill equation to the data was increased when Phe160 was exchanged by alanine or tyrosine, whereas the apparent $K_{\mathrm{m}}$ value for $\mathrm{TEA}^{+}$was not changed (Figs. 3A and 4A; Table 3 ). Although Hill coefficients at approximately 1 were determined for $\mathrm{MPP}^{+}$uptake by wild-type rOCT1 and mutant F160A and for TEA $^{+}$uptake by wild-type rOCT1 and mutants F160A and F160Y, a negative cooperativity was obtained for $\mathrm{MPP}^{+}$uptake by mutant F160Y (Figs. 3A and 4A). In HEK293 cells stably transfected with mutant W218Y, the apparent $K_{\mathrm{m}}$ value for $\mathrm{MPP}^{+}$uptake was strongly decreased compared with wild-type rOCT1 and a negative cooperativity was induced, whereas the apparent $K_{\mathrm{m}}$ and Hill coefficient for $\mathrm{TEA}^{+}$uptake remained unaltered (Figs. 3B and

measured without and with the addition of nonradioactive $\mathrm{MPP}^{+}$. The total concentrations of $\mathrm{MPP}^{+}$are indicated on the abscissa. Mean \pm S.D. values of three or four independent experiments are shown. The data were normalized to uptake of $12.5 \mathrm{nM} \mathrm{MPP}{ }^{+}$. The replacement curves of $\left[{ }^{3} \mathrm{H}\right]$ $\mathrm{MPP}^{+}$uptake by nonradioactive $\mathrm{MPP}^{+}$were obtained by fitting the Hill equation to the data. Mean \pm S.D. values of Hill coefficients are indicated that were determined by fitting the Hill equation to individual experiments. $\bullet P<0.05$, for difference to the Hill coefficient of wild-type rOCT1 determined by Student's $t$ test. $\Delta$ Mean value of Hill coefficient is more than $2 \times$ the S.D. below 1 . 

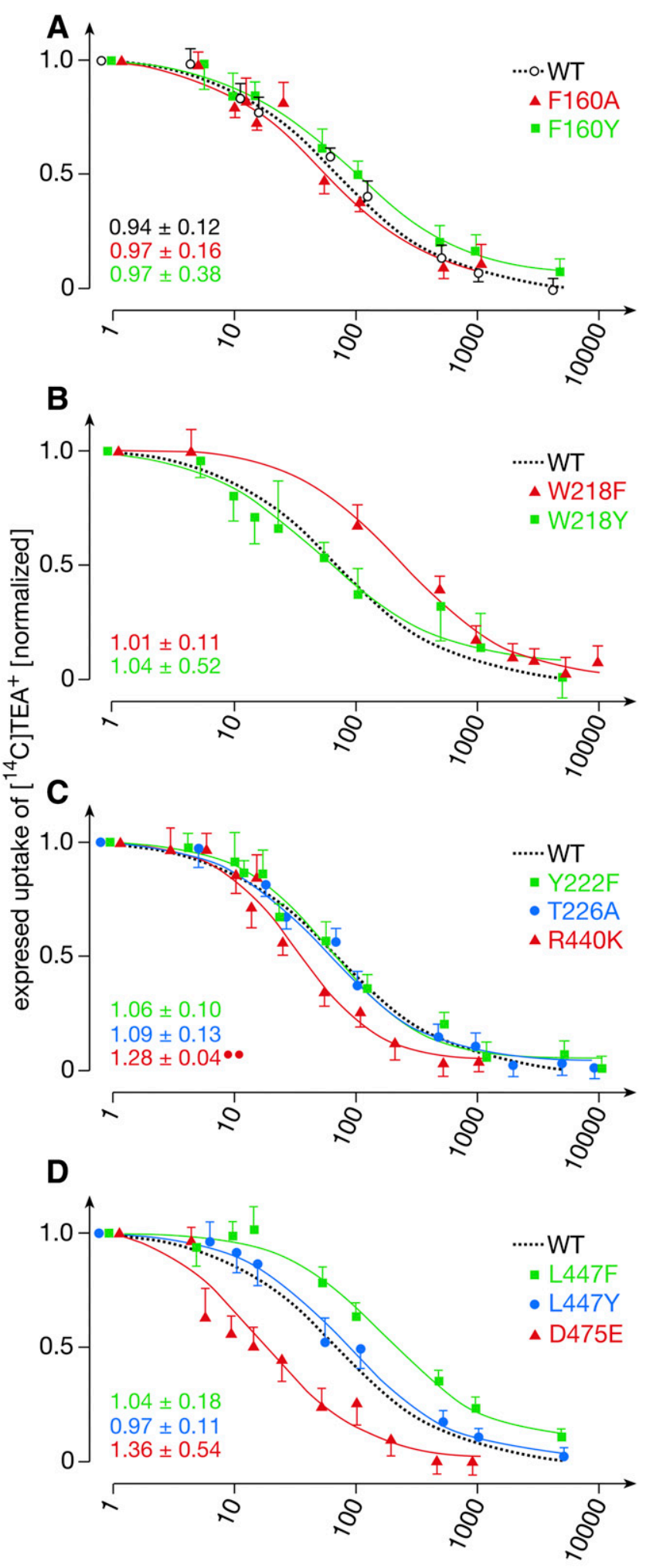

$\mathrm{TEA}^{+}[\mu \mathrm{M}]$

Fig. 4. Substrate dependence of initial rates of $\mathrm{TEA}^{+}$uptake mediated by wild-type rOCT1 and rOCT1 mutants expressed in HEK293 cells. (A) Effects of mutations of Phe160. (B) Effects of mutations of Trp218. (C) Effects of mutations of Tyr222, Thr226, and Arg440. (D) Effects of mutations of Leu447 and Asp475. In stably transfected HEK293 cells, the initial uptake rates of $1 \mu \mathrm{M} \mathrm{TEA}^{+}$traced with $\left[{ }^{14} \mathrm{C}^{\mathrm{TEA}}{ }^{+}\right.$were measured in the presence of different concentrations of nonradioactive $\mathrm{TEA}^{+}$. The total concentrations of TEA are indicated on the abscissa. Mean \pm S.D. values of three or four independent experiments are shown. The
4B; Table 3). When Trp218 was replaced by phenylalanine, the apparent $K_{\mathrm{m}}$ value for $\mathrm{MPP}^{+}$uptake and the Hill coefficient remained unchanged; however, the apparent $K_{\mathrm{m}}$ value for $\mathrm{TEA}^{+}$uptake was increased. In mutant W218L, no statistically significant $\mathrm{TEA}^{+}$uptake could be detected, whereas the apparent $K_{\mathrm{m}}$ for $\mathrm{MPP}^{+}$uptake was increased. The apparent $K_{\mathrm{m}}$ values for $\mathrm{MPP}^{+}$and $\mathrm{TEA}^{+}$uptake and the respective Hill coefficients were not altered when Tyr222 was replaced by phenylalanine (Figs. 3C and 4C; Table 3). In mutant T226A compared with wild-type, the apparent $K_{\mathrm{m}}$ value for $\mathrm{MPP}^{+}$ uptake was increased and a negative cooperativity was induced, whereas the apparent $K_{\mathrm{m}}$ value and Hill coefficient for TEA $^{+}$uptake remained unchanged (Figs. $3 \mathrm{C}$ and $4 \mathrm{C}$; Table 3 ). In mutants R440K, L447F, L447Y, and D475E compared with wild-type, the apparent $K_{\mathrm{m}}$ value for $\mathrm{MPP}^{+}$uptake remained unchanged; however, a negative cooperativity was induced in D475E (Fig. 3, C and D; Table 3). The apparent $K_{\mathrm{m}}$ value for $\mathrm{TEA}^{+}$uptake compared with wild-type was decreased in mutants R440K and D475E, increased in mutant L447F, and unchanged in mutant L447Y. The respective Hill coefficient was increased in mutant R440K and not altered in mutants L447F, L447Y, and D475E (Fig. 4, C and D; Table 3). Considering that Phe160, Trp218, Arg440, Leu447, and Asp475 have been located in our 3D models to the outwardand inward-open binding cleft whereas Thr226 has been only assigned to the inward-open cleft (Popp et al., 2005; Volk et al., 2009), and assuming that extracellular substrate binding rather than intracellular substrate dissociation determines the apparent $K_{\mathrm{m}}$ measured under trans-zero conditions (see Discussion), the data may be interpreted as follows: the effects of the mutations of Trp218 on apparent $K_{\mathrm{m}}$ values for MPP ${ }^{+}$ and $\mathrm{TEA}^{+}$uptake suggest that Trp218 interacts directly with both substrates in the outward-open cleft. Direct interaction of $\mathrm{MPP}^{+}$with Phe160 in the outward-open cleft is also suggested by the effects of mutations on the apparent $K_{\mathrm{m}}$ values for $\mathrm{MPP}^{+}$uptake, whereas direct interactions of TEA ${ }^{+}$with Arg440, Leu447, and Asp475 are suggested by altered $K_{\mathrm{m}}$ values observed for $\mathrm{TEA}^{+}$uptake. The Hill coefficients different from 1 observed for $\mathrm{MPP}^{+}$uptake in mutants F160Y, W218Y, and D475E suggest the existence of two transport-relevant binding sites for $\mathrm{MPP}^{+}$in which cooperative interactions are induced by the respective mutations. The effect of the mutation of Thr226 on the $K_{\mathrm{m}}$ for MPP ${ }^{+}$uptake may be due to an allosteric effect on substrate binding to the outward-open cleft.

Different Effects of Mutations in rOCT1 on IC $_{50}$

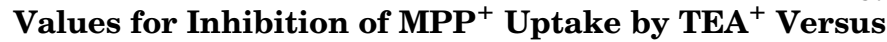
Apparent $K_{m}$ Values of TEA $^{+}$Uptake. Measurements with rOCT1, rOCT1(Y222F), and rOCT1(D475E) presented in Table 1 indicate that under identical experimental conditions partially different values were determined for the apparent $K_{\mathrm{m}}$ value of $\mathrm{TEA}^{+}$uptake versus the respective $\mathrm{IC}_{50}$ value for the inhibition of $0.1 \mu \mathrm{M} \mathrm{MPP}^{+}$uptake by TEA ${ }^{+}$. In some cases, different effects of mutagenesis on the apparent

data were normalized to the uptake of $1 \mu \mathrm{M} \mathrm{TEA}^{+}$. The replacement curves of $\left[{ }^{14} \mathrm{C}\right] \mathrm{TEA}^{+}$uptake by nonradioactive $\mathrm{TEA}^{+}$curves were obtained by fitting the Hill equation to the data. Mean \pm S.D. values of Hill coefficients are indicated that were determined by fitting the Hill equation to individual experiments. $\bullet \bullet P<0.01$, for difference to the Hill coefficient of wildtype rOCT1 determined by Student's $t$ test. 
TABLE 2

Influence on the substrate concentration used for uptake measurement on affinity of $\mathrm{TBuA}^{+}$for inhibition of $\mathrm{MPP}^{+}$uptake mediated by rOCT1 wild-type and two rOCT1 mutants

Initial uptake of different concentrations of $\mathrm{MPP}^{+}$into HEK293 cells stably transfected with rOCT1, rOCT1(Y222F), or rOCT1(D475E) was measured in the presence of different concentrations of $\mathrm{TBuA}^{+}$, and the $\mathrm{IC}_{50}$ values for $\mathrm{TBuA}^{+}$ inhibition were determined by fitting the Hill equation to data of individual experiments. Mean \pm S.D. values of three or four experiments are shown. The compiled uptake measurements and the calculated Hill coefficients are shown in Fig. 2.

\begin{tabular}{|c|c|c|c|}
\hline \multirow{2}{*}{ Transporter } & \multicolumn{3}{|c|}{$\begin{array}{c}\text { IC }_{50} \text { Values for Inhibition of } \mathrm{MPP}^{+} \mathrm{Uptake}_{\text {by }} \mathrm{TBuA}^{+} \text {Using Different Concentrations of } \\
\mathrm{MPP}^{+}\end{array}$} \\
\hline & $100 \mathrm{nM} \mathrm{MPP}{ }^{+}$ & $12.5 \mathrm{nM} \mathrm{MPP}^{+}$ & $0.25 \mathrm{nM} \mathrm{MPP}^{+}$ \\
\hline rOCl & $1.14 \pm$ & $0.26 \pm 0.01 \mu \mathrm{M} \# \#$ & $0.57 \pm 0$ \\
\hline rOCT1 $(\mathrm{Y} 222 \mathrm{~F})$ & $0.30 \pm 0.03 \mu \mathrm{M}^{* * *}$ & $0.27 \pm 0.02 \mu \mathrm{M}$ & $0.36 \pm 0.14 \mu \mathrm{M}$ \\
\hline rOCT1(D475E) & $0.72 \pm 0.13 \mu \mathrm{M}^{* *}$ & $0.17 \pm 0.04 \mu \mathrm{M}^{* *}, \Delta \Delta, \bullet \bullet \bullet$ & $6.80 \pm 0.68 \mu \mathrm{M}^{* * *}, \# \# \#$ \\
\hline
\end{tabular}

WT, wild-type.

ANOVA with post hoc Tukey test: $* * P<0.01$; ***P $<0.001$ for difference to rOCT1 measured with the same concentration of $\mathrm{MPP}^{+} ; \# P<0.05 ; \# \# \# P<0.001$ for difference to the $\mathrm{IC}_{50}$ value obtained with $100 \mathrm{nM} \mathrm{MPP}^{+} ; \cdots P P<$ 0.001 , for difference to the $\mathrm{IC}_{50}$ value obtained with $0.25 \mathrm{nM} \mathrm{MPP}^{+}$. Student's $t$ test: $\Delta \Delta P<0.01$ for difference to the $\mathrm{IC}_{50}$ value obtained with $100 \mathrm{nM} \mathrm{MPP}{ }^{+} ; "{ }^{\prime} P<0.01$ for difference to the $\mathrm{IC}_{50}$ value obtained with $0.25 \mathrm{nM} \mathrm{MPP}^{+}$.

$K_{\mathrm{m}}$ value versus the respective $\mathrm{IC}_{50}$ value were observed. These data indicate complex interactions between $\mathrm{MPP}^{+}$and $\mathrm{TEA}^{+}$that are influenced by single point mutations. To evaluate the impact of all investigated mutations on these interactions between $\mathrm{MPP}^{+}$and $\mathrm{TEA}^{+}$, we also measured the $\mathrm{IC}_{50}$ values for inhibition of the uptake of $0.1 \mu \mathrm{M} \mathrm{MPP}{ }^{+}$by $\mathrm{TEA}^{+}$after mutation of Phe160, Trp218, Thr226, Arg440, or Leu447. The data obtained for wild-type rOCT1 and all investigated mutants are shown in Supplemental Fig. 4. In Supplemental Table 1, a comparison between the $\mathrm{IC}_{50}$ values for TEA ${ }^{+}$inhibition of $\mathrm{MPP}^{+}$uptake and the apparent $K_{\mathrm{m}}$ values for TEA ${ }^{+}$uptake is presented. In wild-type rOCT1, the $\mathrm{IC}_{50}$ value is $37 \%$ smaller than the apparent $K_{\mathrm{m}}$ value. For mutants F160A, W218F, W218Y, R440K, and L447Y, similar $\mathrm{IC}_{50}$ and apparent $K_{\mathrm{m}}$ values were determined, whereas 2.7fold to 3.8 -fold diverging $\mathrm{IC}_{50}$ and apparent $K_{\mathrm{m}}$ values were obtained for mutants F160Y, Y222F, T226A, L447F, and D475E. In consequence, these mutations induced different effects on the $\mathrm{IC}_{50}$ and apparent $K_{\mathrm{m}}$ values. Whereas for the inhibition of $\mathrm{MPP}^{+}$uptake by $\mathrm{TEA}^{+}$in wild-type rOCT1 and most mutants a Hill coefficient of approximately 1 one was determined, positive cooperativity was observed for mutant F160Y and negative cooperativity was observed for mutants W218L, T226A, and L447F (Supplemental Fig. 4). The observations suggest the effects of mutations of Phe160, Tyr222, Thr226, Leu447, and Asp475 on simultaneous binding of TEA ${ }^{+}$and $\mathrm{MPP}^{+}$, which allow mutual direct and/or allosteric interactions between the two substrates.

Effects of Mutations in rOCT1 on IC $_{50}$ Values for Inhibition of MPP ${ }^{+}$Uptake by Nontransported Inhibitors. Next, we determined whether the above-mentioned mutations in rOCT1 influence the inhibition of 1- or 5-second uptake of $0.1 \mu \mathrm{M} \mathrm{MPP}^{+}$by $\mathrm{TBuA}^{+}, \mathrm{TPeA}^{+}$, and corticosterone (Figs. 5-7; Table 4). Since these inhibitors are not transported by rOCT1 (Nagel et al., 1997; Gorboulev et al., 1999, 2005; Koepsell et al., 2007; Volk et al., 2009) and passive diffusion during 1- or 5-second incubation can be neglected, the inhibition must be due to binding of the inhibitors to the outward-open cleft of rOCT1. MPP ${ }^{+}$uptake mediated by wild-type rOCT1 was reduced $>90 \%$ by $50 \mu \mathrm{M} \mathrm{TBuA}^{+}$(Fig. 5), $>95 \%$ by $10 \mu \mathrm{M} \mathrm{TPeA}^{+}$(Fig. 6 ), and $>95 \%$ by $200 \mu \mathrm{M}$ corticosterone (Fig. 7). With one exception (inhibition of the mutant W218L by $\mathrm{TPeA}^{+}$) (Fig. 6B), the obtained inhibition curves suggest that the mutations do not diminish maximal inhibition. However, several mutations alter the affinities of the inhibitors for rOCT1, as indicated by altered $\mathrm{IC}_{50}$ values (Table 4). The $\mathrm{IC}_{50}$ values of $\mathrm{TBuA}^{+}, \mathrm{TPeA}^{+}$, and corticosterone were decreased when Asp 475 was replaced by glutamate and altered after the replacement of Trp218 by phenylalanine, tyrosine, and/or leucine. Different effects of the mutations were observed for different inhibitors. For example, in mutant $\mathrm{W} 218 \mathrm{~F}$ the $\mathrm{IC}_{50}$ value for $\mathrm{TBuA}^{+}$was increased 5.3-fold, the $\mathrm{IC}_{50}$ value for $\mathrm{TPeA}^{+}$was decreased 9 -fold, and the $\mathrm{IC}_{50}$ value for corticosterone was increased 2.7-fold. Notably, largely different $\mathrm{IC}_{50}$ values were obtained when $\operatorname{Trp} 218$ was replaced by tyrosine versus phenylalanine, although the replaced amino acids only differ by one hydroxyl group. In mutant $\mathrm{W} 218 \mathrm{Y}$, the $\mathrm{IC}_{50}$ for $\mathrm{TBuA}^{+}$was 10.6 times lower than in $\mathrm{W} 218 \mathrm{~F}$, whereas the $\mathrm{IC}_{50}$ values for $\mathrm{TPeA}^{+}$and corticosterone were increased 6.7-fold and 3.3-fold, respectively. Upon exchange of Phe160 by alanine, the $\mathrm{IC}_{50}$ values for $\mathrm{TBuA}^{+}$ and corticosterone were decreased 2.3-fold and 2.9-fold, respectively, whereas the $\mathrm{IC}_{50}$ value for $\mathrm{TPeA}^{+}$was not changed.

\section{TABLE 3}

Apparent $K_{\mathrm{m}}$ values of $\mathrm{MPP}^{+}$and $\mathrm{TEA}^{+}$transport mediated by rOCT1 wild-type and rOCT1 mutants

Initial uptake rates of nine different concentrations radioactively traced $\mathrm{MPP}^{+}$or $\mathrm{TEA}^{+}$were measured at $37^{\circ} \mathrm{C}$ in stably transfected HEK293 cells and apparent $K_{\mathrm{m}}$ values were determined by fitting the Hill equation to data of individual experiments. Mean values \pm S.D. of three or four separate experiments are shown. The compiled uptake measurements and the calculated Hill coefficients are shown in Figs. 3 and 4.

\begin{tabular}{lcc}
\hline rOCT1 & $\begin{array}{c}\text { Transport of } \mathrm{MPP}^{+} \\
\text {App. } K_{\mathrm{m}}\end{array}$ & $\begin{array}{c}\text { Transport of } \\
\text { TEA } \\
\text { App. } K_{\mathrm{m}}\end{array}$ \\
\hline WT & $4.7 \pm 0.8$ & $\mu \mathrm{M}$ \\
F160A & $10.6 \pm 0.9^{* * *}$ & $67 \pm 9.9$ \\
F160Y & $13.3 \pm 4.6^{* * *}$ & $57 \pm 8.3$ \\
W218F & $5.0 \pm 1.8$ & $84 \pm 22$ \\
W218Y & $0.75 \pm 0.09 \Delta \Delta \Delta, \#$ & $230 \pm 28^{* * *}$ \\
W218L & $11.9 \pm 1.8^{* * *}, \bullet \bullet$ & $61 \pm 7.2 \bullet \bullet$ \\
Y222F & $5.0 \pm 1.8$ & No uptake \\
T226A & $8.8 \pm 1.9 \Delta \Delta$ & $55 \pm 11$ \\
R440K & $4.2 \pm 1.0$ & $60 \pm 7.7$ \\
L447F & $3.1 \pm 0.7$ & $32 \pm 6.0 \Delta \Delta$ \\
L447Y & $5.6 \pm 1.5$ & $167 \pm 23^{* * *}$ \\
D475E & $4.9 \pm 2.0$ & $80 \pm 6.1 \square \square$ \\
\hline
\end{tabular}

App., apparent; WT, wild-type.

ANOVA with post hoc Tukey test: $* * * P<0.001$ difference to wild-type, $\bullet \bullet P<$ 0.001 , difference to W218F, $\square \square \square P<0.001$ difference to L447F; Student's $t$ test $\Delta \triangle P<0.01 ; \Delta \triangle \triangle P<0.001$ difference to wild-type, $\# P<0.05$ difference to W218F. 

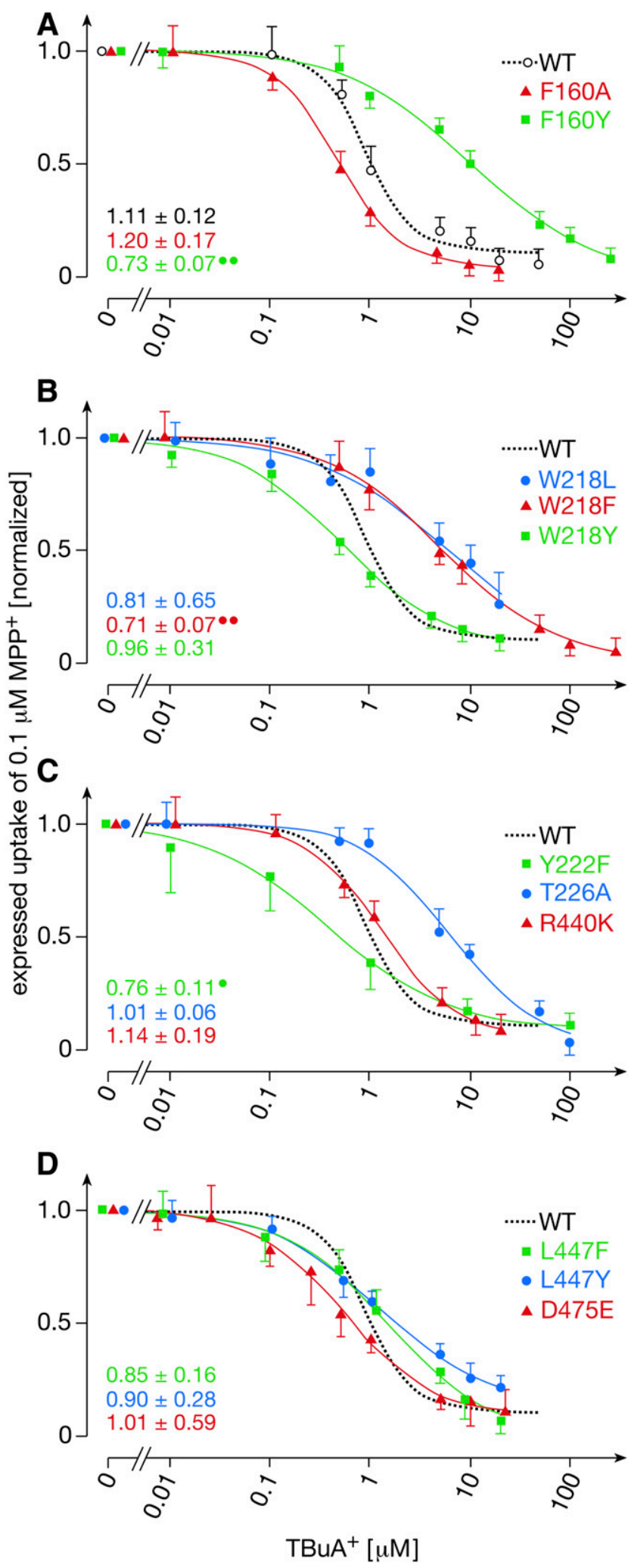

Fig. 5. Inhibition of $\mathrm{MPP}^{+}$uptake mediated by rOCT1 wild-type or rOCT1 mutants by extracellular TBuA ${ }^{+}$. (A) Effects of mutations of Phe160. (B) Effects of mutations of Trp218. (C) Effects of mutations of Tyr222, Thr226, and Arg440. (D) Effects of mutations of Leu447 and Asp475. In stably transfected HEK293 cells, initial uptake rates of $0.1 \mu \mathrm{M} \mathrm{MPP}{ }^{+}$traced with $\left[{ }^{3} \mathrm{H}\right] \mathrm{MPP}^{+}$were measured in the absence and presence of different concentrations of $\mathrm{TBuA}^{+}$. Mean \pm S.D. values of three or four independent experiments are indicated. The data were normalized to $\mathrm{MPP}^{+}$uptake measured in the absence of
The conservative exchange of Phe160 by tyrosine only altered the $\mathrm{IC}_{50}$ value for $\mathrm{TBuA}^{+}$, a 10 -fold increased concentration was required for half-maximal inhibition. In the mutant $\mathrm{T} 226 \mathrm{~A}$, the $\mathrm{IC}_{50}$ values for $\mathrm{TBuA}^{+}$and corticosterone were increased 6.5-fold and 3-fold, respectively, whereas in the variant $\mathrm{L} 447 \mathrm{Y}$ the $\mathrm{IC}_{50}$ values for $\mathrm{TPeA}^{+}$and corticosterone were increased 1.8-fold and 3-fold, respectively.

For inhibition of wild-type rOCT1 and most rOCT1 mutants by $\mathrm{TBuA}^{+}, \mathrm{TPeA}^{+}$, or corticosterone, Hill coefficients at approximately 1 were observed (Figs. 5-7). However, for the inhibition of $\mathrm{MPP}^{+}$uptake by $\mathrm{TBuA}^{+}$, negative cooperativity was induced after replacement of Phe160 by tyrosine, after replacement of Trp218 by phenylalanine, and after replacement of Tyr222 by phenylalanine (Fig. 5). For the inhibition of $\mathrm{MPP}^{+}$uptake by TPeA ${ }^{+}$, negative cooperativity was induced when Trp218 was replaced by phenylalanine (Fig. 6), whereas for inhibition of $\mathrm{MPP}^{+}$uptake by corticosterone negative cooperativity was observed in mutants $\mathrm{F} 160 \mathrm{Y}, \mathrm{W} 218 \mathrm{~F}$, and L447F (Fig. 7).

The data suggest that Asp475 and Trp218 are directly involved in the binding of $\mathrm{TBuA}^{+}, \mathrm{TPeA}^{+}$, and corticosterone to the outward-open cleft, that Leu447 participates in binding of TPeA and corticosterone to the outward-open cleft, and that Phe160 is directly involved in the binding of $\mathrm{TBuA}^{+}$from the extracellular side. The observation of cooperativity for the inhibition of $\mathrm{MPP}^{+}$uptake by $\mathrm{TBuA}^{+}, \mathrm{TPeA}^{+}$, and corticosterone in some mutants suggests that $\mathrm{rOCT} 1$ contains more than one extracellular binding sites for each of these inhibitors. Because Thr226 has been found to be accessible at the inward-open but not at the outward-open cleft of our 3D structural models of rOCT1, the exchange of Thr226 by alanine in this position probably exhibits an allosteric effect on the extracellular binding sites of $\mathrm{TBuA}^{+}$and corticosterone.

Re-evaluation of Previous Model-Predicted Locations of the Phe160, Trp218, Arg440, and Asp475 within the Outward-Open Cleft of rOCT1 Using a New Model of hOCT1. The mechanisms proposed to explain the observed effects of the analyzed mutations depend largely on the assigned locations of the respective residues in the outward-open cleft and hence depend on the quality of the outward-facing 3D homology rOCT1 model (Gorbunov et al., 2008; Volk et al., 2009). Our outward-facing 3D model was built manually on the basis of a 3D homology rOCT1 model in the inward-facing conformation that was modeled from the crystal structure of lactose permease (Abramson et al., 2003; Popp et al., 2005). To obtain the outward-open conformation, we assumed (and used) a rigid-body movement of the first (Nterminal) six helices with respect to the last (C-terminal) six helices, which transformed the inward-open confirmation into an outward-open conformation. Minor manual rebuilding allowing for some intrahelical motions and drifting of individual domains was necessary to remove van der Waals clashes. A very similar helix rearrangement has been proposed, modeled, and also experimentally verified for lactose

$\mathrm{TBuA}^{+}$. The curves were obtained by fitting the Hill equation to the data. Mean \pm S.D. values of Hill coefficients are indicated that were determined by fitting the Hill equation to individual experiments. $\bullet P<0.05 ; \bullet \bullet P<0.01$, for difference to the Hill coefficient of wild-type rOCT1 determined by Student's $t$ test. 

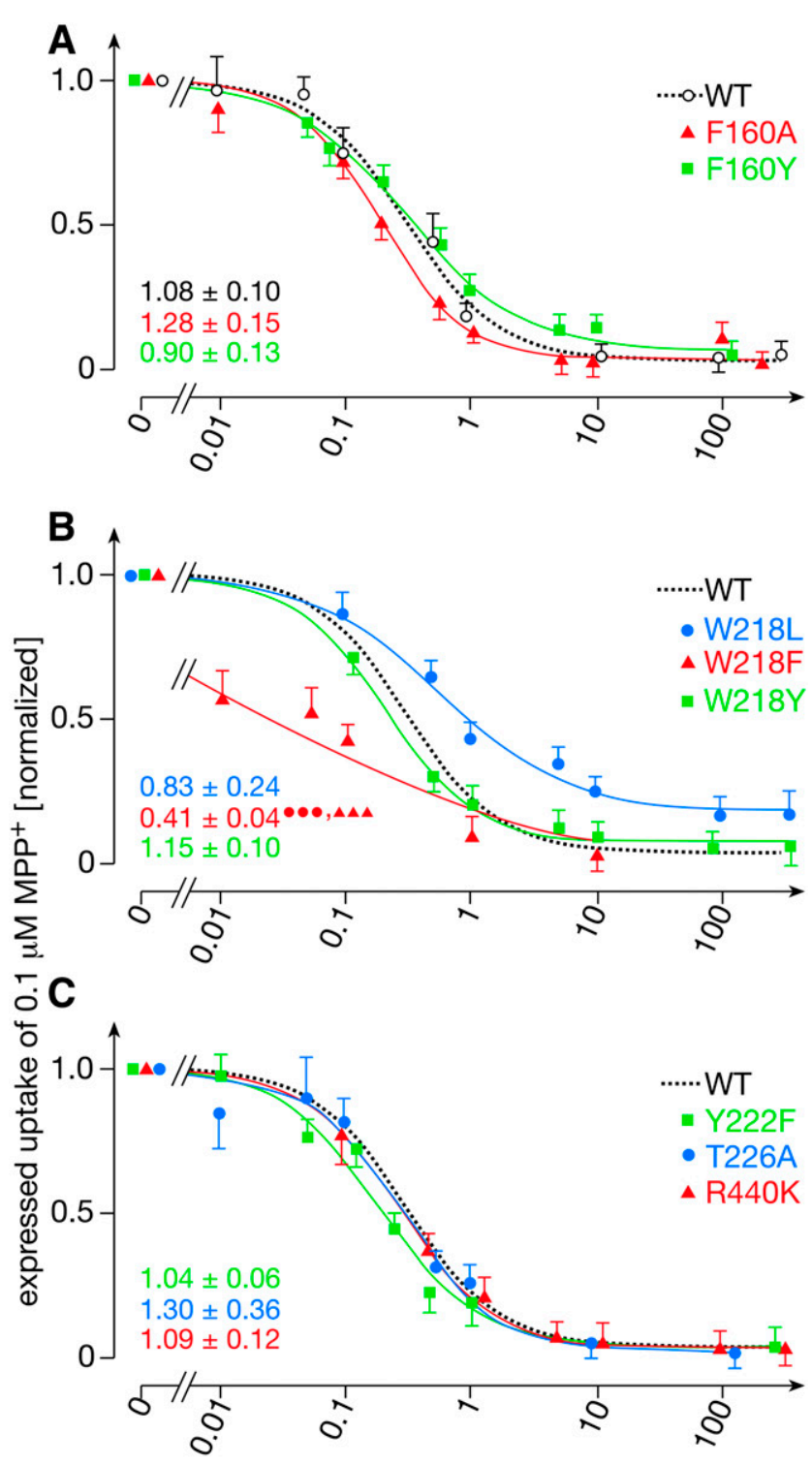

D

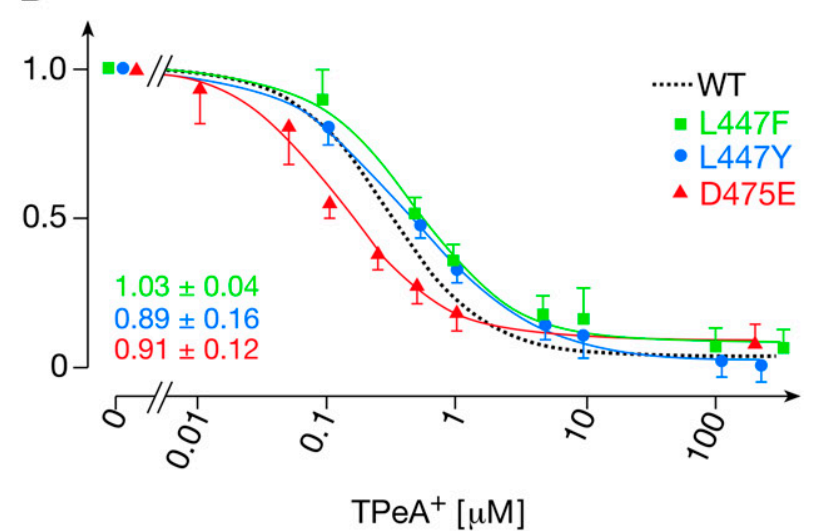

Fig. 6. Inhibition of $\mathrm{MPP}^{+}$uptake mediated by wild-type rOCT1 or rOCT1 mutants by extracellular TPeA ${ }^{+}$. (A) Effects of mutations of Phe160. (B) Effects of mutations of Trp218. (C) Effects of mutations of Tyr222, Thr226, and Arg440. (D) Effects of mutations of Leu447 and Asp475. In stably transfected HEK293 cells, initial uptake rates of $0.1 \mu \mathrm{M} \mathrm{MPP}^{+}$traced with $\left[{ }^{3} \mathrm{H}\right] \mathrm{MPP}^{+}$were measured in the absence and presence of different concentrations of $\mathrm{TPeA}^{+}$. Mean \pm S.D. values of three or four independent experiments are indicated. The measurements were performed, and the permease (Ermolova et al., 2006; Holyoake and Sansom, 2007; Kaback et al., 2007). Recently, an outward-facing partially closed structure of hOCT1 was modeled using crystal structures of various transporters from the MFS superfamily as templates (Dakal et al., 2017). With the exception of Leu447 (with isoleucine in the corresponding position of hOCT1), the amino acids of rOCT1 investigated in this article are conserved in hOCT1 (Supplemental Fig. 5). The positions of the amino acids mutated in our study that were assigned to the outward-facing cleft are highly similar between our rOCT1 3D model and the novel 3D model of hOCT1 in an outward-facing conformation (Supplemental Fig. 6). Both models predict that Phe160, Trp218 (Trp217), Arg440 (Arg439), Leu447 (Ile446). and Asp475 (Asp474) are located within the extracellular cleft and presumably are accessible from the extracellular side. In Fig. 8, views from the extracellular space into the outwardfacing cleft of our 3D rOCT1 model are presented and the mutated amino acids, which are accessible from the extracellular space, are indicated. In the model, Phe160, Trp218, Arg440, Leu447, and Asp475 are surface accessible in the outward-open cleft. Trp218 and Asp475 are located in close proximity with Phe160 and Leu447 in nearby positions. In contrast, Arg440 is located at some distance on the opposite side of the cleft.

\section{Discussion}

We report that the experimental conditions used for studying the transport and inhibition of rOCT1 can have dramatic impact on the effects of mutations on affinities. The data are relevant for in vitro characterization of drug interactions with OCTs and OCT mutants and for molecular interpretation of mutagenesis experiments. Measuring initial uptake rates under trans-zero conditions in stably transfected HEK293 cells, we identified the interactions of inhibitors and determined the probable interactions of substrates with five amino acids in the outward-open cleft of rOCT1. Trp218 and Asp475 most likely interact with the nontransported inhibitors $\mathrm{TBuA}^{+}, \mathrm{TPeA}^{+}$, and corticosterone, and presumably also with one or two substrates (Asp475 with TEA, and Trp218 with $\mathrm{MPP}^{+}$and $\mathrm{TEA}^{+}$). Phe160 most likely interacts with $\mathrm{TBuA}^{+}$ and corticosterone, and probably also with $\mathrm{MPP}^{+}$, whereas Leu447 most likely interacts with $\mathrm{TPeA}^{+}$, and probably also with $\mathrm{TEA}^{+}$. Arg440 probably interacts with $\mathrm{TEA}^{+}$. Fitting the Hill equation to data describing the concentration dependence of $\mathrm{MPP}^{+}$uptake, Hill coefficients smaller than one were determined for four mutants. This suggests the existence of two transport-relevant, low-affinity $\mathrm{MPP}^{+}$binding sites that exhibit negative cooperativity in the respective mutants. Recent experiments support this interpretation (unpublished data). Measuring $\mathrm{MPP}^{+}$binding to rOCT1 and rOCT1 mutants, which were reconstituted into lipid nanodiscs (Bayburt and Sligar, 2002), and measuring $\mathrm{MPP}^{+}$uptake into proteoliposomes containing rOCT1 and rOCT1 mutants, we observed that rOCT1 contains two low-affinity, transportrelevant $\mathrm{MPP}^{+}$binding sites per rOCT1 monomer that have

data were calculated and are presented as in Fig. 5. Student's $t$ tests: $\bullet \bullet P<0.001$, for difference to the Hill coefficient of wild-type rOCT1, $\mathbf{\Delta \Delta \Delta} P<0.001$, for difference to the Hill coefficient of mutant W218Y. 

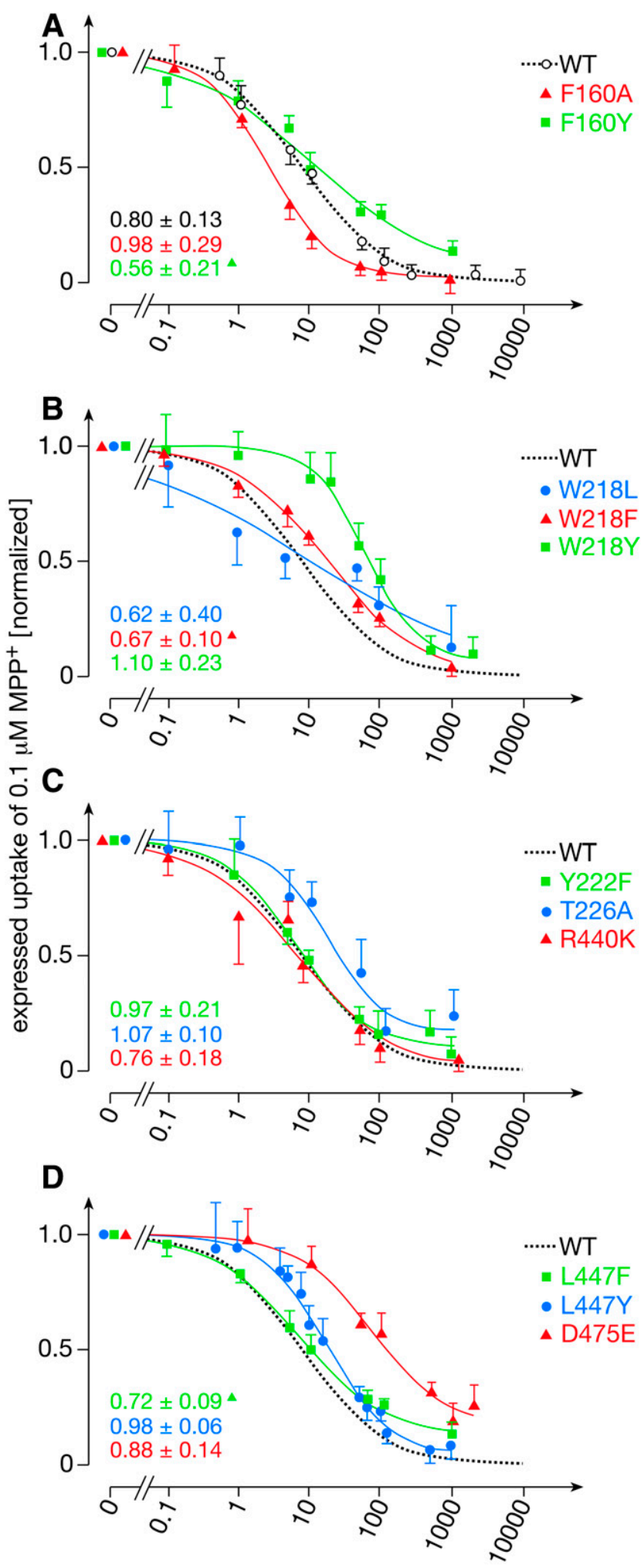

corticosterone $^{+}[\mu \mathrm{M}]$

Fig. 7. Inhibition of $\mathrm{MPP}^{+}$uptake mediated by wild-type $\mathrm{rOCT} 1$ or $\mathrm{rOCT} 1$ mutants by extracellular corticosterone. (A) Effects of mutations of Phe160. (B) Effects of mutations of Trp218. (C) Effects of mutations of Tyr222, Thr226, and Arg440. (D) Effects of mutations of Leu447 and Asp475. In stably transfected HEK293 cells, initial uptake rates of $0.1 \mu \mathrm{M}$ $\mathrm{MPP}^{+}$traced with $\left[{ }^{3} \mathrm{H}\right] \mathrm{MPP}^{+}$were measured in the absence and presence of different concentrations of corticosterone. Mean \pm S.D. values of three or
TABLE 4

Inhibition of $\mathrm{MPP}^{+}$uptake via rOCT1 wild-type (WT) and rOCT1 mutants by three nontransported inhibitors

Uptake measurements were performed at $37^{\circ} \mathrm{C}$ in stably transfected HEK293 cells using an incubation time of $1 \mathrm{~s}$, except in mutant D475E where a 5-s incubation was performed. Uptake of $0.1\left[{ }^{3} \mathrm{H}\right] \mathrm{MPP}^{+}$was measured in the presence of different concentrations of $\mathrm{TBuA}^{+}, \mathrm{TPeA}^{+}$, and corticosterone. Mean \pm S.D. values of three to five separate experiments are shown. The compiled uptake measurements and the calculated Hill coefficients are shown in Figs. 5-7.

\begin{tabular}{lcll}
\hline rOCT1 & \multicolumn{1}{c}{$\mathrm{TBuA}^{+} \mathrm{IC}_{50}$} & \multicolumn{1}{c}{$\mathrm{TPeA}^{+} \mathrm{IC}_{50}$} & \multicolumn{1}{c}{ Corticosterone $\mathrm{IC}_{50}$} \\
\hline & & \multicolumn{1}{c}{$\mu \mathrm{M}$} \\
WT & $0.97 \pm 0.22$ & $0.27 \pm 0.05$ & $6.9 \pm 1.57$ \\
$\mathrm{~F} 160 \mathrm{~A}$ & $0.42 \pm 0.04 \#$ & $0.19 \pm 0.04$ & $2.36 \pm 0.59 \# \#$ \\
$\mathrm{~F} 160 \mathrm{Y}$ & $9.8 \pm 1.9^{* * *}$ & $0.33 \pm 0.09$ & $8.65 \pm 0.75$ \\
W218F & $5.1 \pm 0.20^{* * *}$ & $0.03 \pm 0.01^{* * *}$ & $18.8 \pm 4.3^{* *}$ \\
W218Y & $0.48 \pm 0.06 \#, \bullet \bullet \bullet$ & $0.20 \pm 0.03 \bullet \bullet$ & $61.5 \pm 11.6^{* * *}, \bullet \bullet$ \\
W218L & $5.13 \pm 1.04^{* * *}$ & $0.41 \pm 0.05 \# \#, \bullet \bullet \bullet$ & $4.07 \pm 1.29 \bullet \bullet$ \\
Y222F & $0.28 \pm 0.06 \# \#$ & $0.18 \pm 0.02$ & $7.07 \pm 1.69$ \\
T226A & $6.4 \pm 1.6^{* * *}$ & $0.30 \pm 0.01$ & $20.7 \pm 6.0^{* *}$ \\
R440K & $1.28 \pm 0.38$ & $0.26 \pm 0.05$ & $6.00 \pm 1.39$ \\
L447F & $1.40 \pm 0.29$ & $0.51 \pm 0.09^{* *}$ & $8.12 \pm 2.32$ \\
L447Y & $1.04 \pm 0.14$ & $0.49 \pm 0.07^{* *}$ & $20.6 \pm 4.0^{* *,}$, \\
D475E & $0.49 \pm 0.10 \#$ & $0.12 \pm 0.03^{*}$ & $2.26 \pm 0.31 \# \#$ \\
\end{tabular}

WT, wild-type

ANOVA with post hoc Tukey test: $* * P<0.01$, $* * * P<0.001$ difference to wildtype; $\bullet_{P}<0.01, \bullet^{\bullet} P<0.001$ difference to W218F; $\square P<0.05$ difference to L447F; Student's $t$ test: $\# P<0.05$, \#\# $<0.01$ difference to wild-type.

similar dissociation constants and are located in the modeled outward-facing cleft of rOCT1.

Our interpretations concerning the interactions of the inhibitors or substrates with amino acids in the outwardopen cleft are based on two or three presumptions, respectively. First, it is presumed that Phe160, Trp218, Leu447, Arg440, and Asp475 are located at the inner surface of the outward-facing cleft of rOCT1 as predicted by modeling (see Fig. 8). The second presumption is that the changes in affinities observed in the mutants reflect direct effects on the binding of the substrates and/or inhibitors to the respective amino acids. Our interpretation concerning the interaction of the substrates is additionally based on the presumption that the determined apparent $K_{\mathrm{m}}$ values measuring initial uptake rates reflect the binding affinities of these compounds to the extracellular-facing cleft.

Due to the limited sequence homology of rOCT1 and hOCT1 to their structure templates and the fact that the conformational variability of the transporters is not known, the predictive potential of the models is inherently limited. However, considering that the models of rOCT1 and hOCT1 were derived from rather different modeling techniques and are based on quite different structure templates, the finding of highly similar positions for the five amino acid residues in the outward-facing clefts might serve as an indication that these models come close to the real OCT1 structure and our first presumption is justified (see Supplemental Fig. 6).

Although a potential involvement of allosteric effects on the binding of inhibitors is indicated by the observation of affinity changes of nontransported inhibitors upon mutation of Thr226, which is not accessible from the extracellular side (Supplemental Fig. 6; Table 4), it is more likely that the nontransported inhibitors directly interact with Phe160,

four independent experiments are indicated. The measurements were performed, and the data were calculated and presented as in Fig. 5. $\mathbf{\Delta M e a n}$ value of Hill coefficient is more than $2 \times$ S.D. values below 1 . 
A

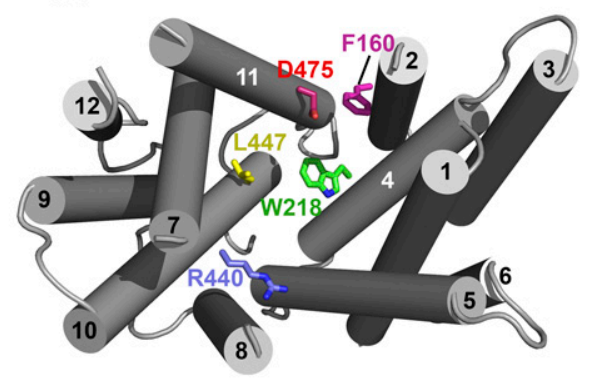

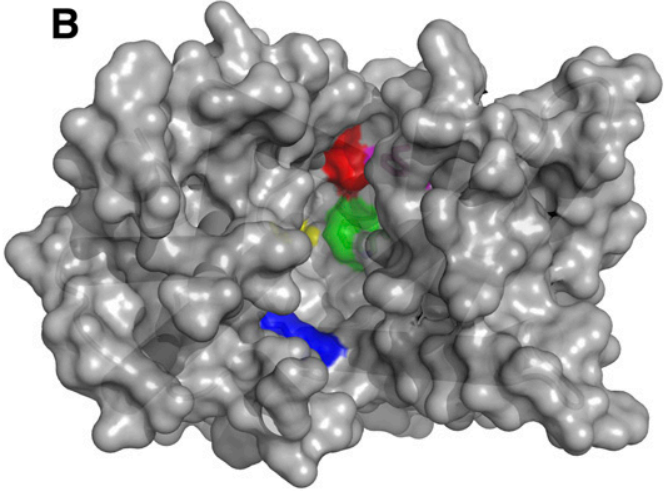

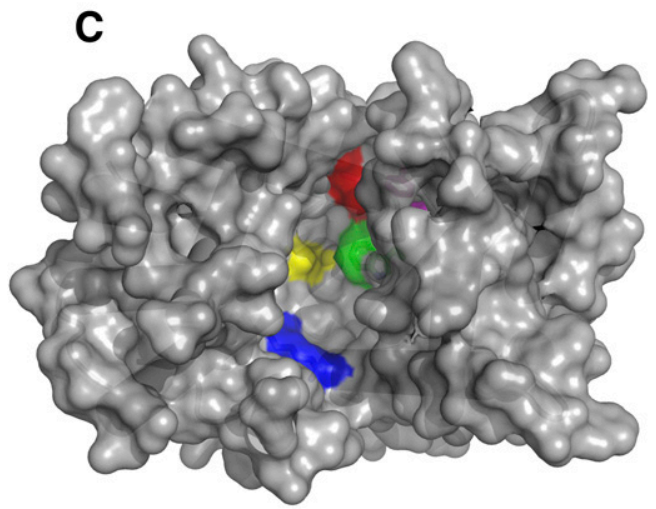

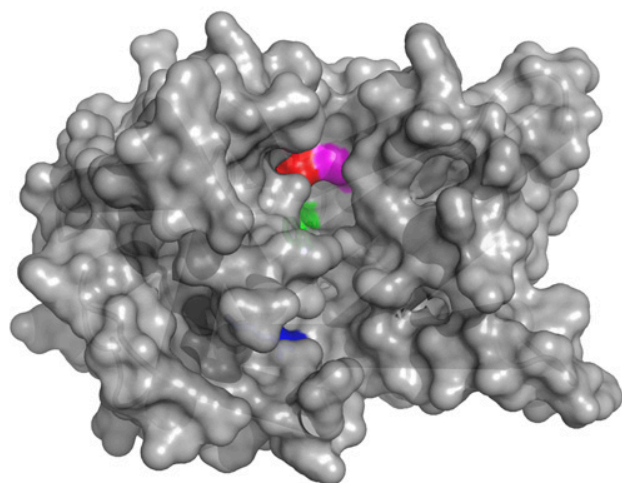

Fig. 8. Views from the extracellular side on the 3D structural model of the outward-facing conformation or rOCT1 with indicated positions of Phe160, Trp218, Arg440, Leu447, and Asp475. (A) Secondary structure cartoon in which the 12 transmembrane helices are shown as solid tubes and numbered accordingly. The residues are shown as sticks, with Phe160 shown in magenta, Trp218 shown in green, Arg440 shown in blue, Leu 447 shown in yellow, and Asp475 shown in red. (B) Surface representation of (A) using the same color coding. (C) Surface representations of the outward-facing conformation of rOCT1 viewed from different angles in which the surface representation of Phe160 or Leu447 becomes visible. Trp218 and Asp475 with nearby Phe160 and Leu447 form one surface patch. Arg440 in a distant location is also well accessible to the surface.

Trp218, Arg440, Leu447, and Asp475. Thus, according to our model these amino acids are located at the surface of the outward-open cleft (Fig. 8; Supplemental Fig. 6), and mutating these amino acids affects both the $\mathrm{IC}_{50}$ values for nontransported inhibitors and the apparent $K_{\mathrm{m}}$ values of substrates (Tables 3 and 4). In addition, the exchange of Phe160, Trp218, and Leu447 for different amino acids alters the affinities of structurally diverse nontransported inhibitors in different ways (Table 4).

The third presumption that the $K_{\mathrm{m}}$ values reflect the affinities of $\mathrm{MPP}^{+}$and $\mathrm{TEA}^{+}$binding to the outward-facing cleft, probably matches reality, because we measured initial uptake rates, and OCT1 operates as a cellular uptake system, which is supposed to have a higher affinity for extracellular substrate binding compared with intracellular substrate dissociation (Koepsell, 2011).

We showed that the experimental conditions used for in vitro uptake measurements in transfected HEK293 cells have dramatic effects on the affinities of substrates and inhibitors. Not only were the apparent $K_{\mathrm{m}}$ values of rOCT1mediated cation transport and the $\mathrm{IC}_{50}$ values for the inhibition of transport different, but so also were the effects of mutations on apparent $K_{\mathrm{m}}$ values and $\mathrm{IC}_{50}$ values when uptake was measured in dissociated HEK293 cells using 1-, 5 -, or 10-second incubation times compared with uptake measurements performed with confluent HEK293 cells using a 2-minute incubation time. The differences may be due to differing regulatory states of OCT1 in dissociated versus confluent cells, to different impacts of unstirred layer effects, and/or to the assessment of different transport modes. When dissociated HEK293 cells expressing rOCT1 or hOCT1 were incubated for 1-3 seconds with radioactively labeled $\mathrm{MPP}^{+}$ while performing vigorous shaking, initial linear uptake rates were determined that are higher compared with the uptake rates observed later on (Busch et al., 1996a; Minuesa et al., 2009). These initial uptake rates represent a uniport transport mode involving extracellular substrate binding, substrate translocation, intracellular substrate dissociation, and reorientation of the empty transporter (Koepsell 2011). In performing a 2-minute incubation, the transport mode may change during incubation because of an increase of intracellular substrate. This may lead to transporter-mediated efflux of radioactive substrate resulting in a slowed-down net uptake of radioactivity. It is noteworthy that the apparent linearity of radioactive uptake, which has been reported for cell layers using incubation times between 30-60 seconds and 2-5 minutes (Bednarczyk et al., 2003; Cheng et al., 2011; Chen et al., 2017), did not exclude higher uptake rates within the first seconds. Measuring the uptake of $0.1 \mu \mathrm{M}$ radioactively labeled $\mathrm{MPP}^{+}$in monolayers of HEK293 cells stably transfected with rOCT1 or hOCT1 between incubation times of 30 seconds and 10 minutes, we observed a relatively high cell-associated $\mathrm{MPP}^{+}$concentration at 30 seconds that is most probably due to a rapid initial uptake rate (Busch et al., 1996a; Minuesa et al., 2009) and a much slower linear uptake between 30 seconds and 2 minutes (Supplemental Fig. 7). Because 
mutations may change cation import and cation export differently and because net uptake of radioactive substrate observed after a 2-minute incubation probably reflects the difference between uptake and efflux of the radioactive substrate, it is difficult to explain the functional effects of mutations observed after a 2-minute incubation on the molecular level.

Recently, we observed that the uptake of $\mathrm{MPP}^{+}$in HEK293 cells stably transfected with hOCT1 was inhibited with different affinities by pentamidine when $\mathrm{MPP}^{+}$was applied at different concentrations far below the apparent $K_{\mathrm{m}}$ value for $\mathrm{MPP}^{+}$(Minuesa et al., 2017). This indicates that the affinity of inhibitors is not only influenced by the molecular structure of the transported drug as described previously (Belzer et al., 2013; Thévenod et al., 2013), but also by the concentration of the substrate. In the present study, we showed also for rOCT1 that the inhibitor sensitivity is dependent on the substrate concentration. Furthermore, we demonstrated that the substrate concentration also influences the effects of mutations on inhibitor sensitivity. We determined different $\mathrm{IC}_{50}$ values for the inhibition of rOCT1mediated $\mathrm{MPP}^{+}$uptake by $\mathrm{TBuA}^{+}$using different nanomolar concentrations of $\mathrm{MPP}^{+}$and showed that the influence of nanomolar $\mathrm{MPP}^{+}$concentrations on the $\mathrm{IC}_{50}$ value for $\mathrm{TBuA}^{+}$ was altered differently in different OCT1 mutants. The most probable explanation for these properties of the transporter is that differing occupation of high-affinity substrate binding sites induces different allosteric effects on the transportrelevant cation binding sites and that mutations within the transport-relevant sites modulate this allosteric response.

The dramatic impact of experimental conditions on the measured affinities of substrates and inhibitors should be considered for further investigation of the structure-function relationship by mutagenesis, and for in vitro analysis of how polymorphisms influence drug affinities and drug-drug interactions at hOCT1 or the other OCT subtypes (Koepsell, 2015). To characterize the molecular impact of individual amino acids on binding or transport in mutagenesis studies defined transport modes should be analyzed. For example, initial trans-zero uptake may be determined as performed in the present study using short-term incubation of dissociated cells including rigorous shaking to minimize unstirred layer effects. For in vitro characterization of the effects of polymorphisms in hOCT1, human OCT2, or human OCT3 on drug transport or for in vitro characterizations of drug-drug interactions, conditions should be used that reflect the in vivo exposition with organic cations. Hence in vivo transport measured with relatively long incubation times or under equilibrium conditions is more relevant than initial uptake. Measuring the inhibition of OCT-mediated drug transport by a second drug, drug concentrations within the ranges of their free blood concentrations should be used and the tests should be extended to frequently occurring polymorphisms in the respective transporter (Koepsell, 2015).

\section{Acknowledgments}

The authors thank Irina Schatz and Alla Ganscher from the Institute of Anatomy and Cell Biology of the University of Würzburg (Germany) for expert technical assistance and Michael Christof from the Institute of Anatomy and Cell Biology of the University of Würzburg for generating the figures.

\section{Authorship Contributions}

Participated in research design: Koepsell.
Conducted experiments: Gorboulev, Rehman, Albert, Roth, Meyer, Tzvetkov, Mueller.

Performed data analysis: Rehman, Albert, Roth, Meyer, Tzvetkov, Mueller, Koepsell.

Wrote or contributed to the writing of the manuscript: Koepsell.

\section{References}

Abramson J, Smirnova I, Kasho V, Verner G, Kaback HR, and Iwata S (2003) Structure and mechanism of the lactose permease of Escherichia coli. Science $\mathbf{3 0 1}$ : 610-615.

Ahlin G, Chen L, Lazorova L, Chen Y, Ianculescu AG, Davis RL, Giacomini KM, and Artursson P (2011) Genotype-dependent effects of inhibitors of the organic cation transporter, OCT1: predictions of metformin interactions. Pharmacogenomics $J$ 11:400-411.

Ahlin G, Karlsson J, Pedersen JM, Gustavsson L, Larsson R, Matsson P, Norinder U, Bergström CA, and Artursson P (2008) Structural requirements for drug inhibition of the liver specific human organic cation transport protein 1. J Med Chem 51: 5932-5942.

Arndt P, Gorboulev V, Nagel G, Friedrich T, Gambaryan S, Volk C, and Koepsell H (1998) Functional properties of the polyspecific rat organic cation transporter rOCT2. Nova Acta Leopoldina NF 78 306:347-348.

Arndt P, Volk C, Gorboulev V, Budiman T, Popp C, Ulzheimer-Teuber I, Akhoundova A, Koppatz S, Bamberg E, Nagel G, et al. (2001) Interaction of cations, anions, and weak base quinine with rat renal cation transporter rOCT2 compared with rOCT1. Am J Physiol Renal Physiol 281:F454-F468.

Bayburt TH and Sligar SG (2002) Single-molecule height measurements on microsomal cytochrome P450 in nanometer-scale phospholipid bilayer disks. Proc Nat Acad Sci USA 99:6725-6730.

Bednarczyk D, Ekins S, Wikel JH, and Wright SH (2003) Influence of molecular structure on substrate binding to the human organic cation transporter, hOCT1. Mol Pharmacol 63:489-498.

Belzer M, Morales M, Jagadish B, Mash EA, and Wright SH (2013) Substratedependent ligand inhibition of the human organic cation transporter OCT2. $J$ Pharmacol Exp Ther 346:300-310.

Budiman T, Bamberg E, Koepsell H, and Nagel G (2000) Mechanism of electrogenic cation transport by the cloned organic cation transporter 2 from rat. J Biol Chem 275:29413-29420.

Busch AE, Quester S, Ulzheimer JC, Gorboulev V, Akhoundova A, Waldegger S, Lang F, and Koepsell H (1996a) Monoamine neurotransmitter transport mediated by the polyspecific cation transporter rOCT1. FEBS Lett 395:153-156.

Busch AE, Quester S, Ulzheimer JC, Waldegger S, Gorboulev V, Arndt P, Lang F, and Koepsell H (1996b) Electrogenic properties and substrate specificity of the polyspecific rat cation transporter rOCT1. J Biol Chem 271:32599-32604.

Chen EC, Khuri N, Liang X, Stecula A, Chien HC, Yee SW, Huang Y, Sali A, and Giacomini KM (2017) Discovery of competitive and noncompetitive ligands of the organic cation transporter 1 (OCT1; SLC22A1). J Med Chem 60:2685-2696.

Chen L, Takizawa M, Chen E, Schlessinger A, Segenthelar J, Choi JH, Sali A, Kubo M, Nakamura S, Iwamoto Y, et al. (2010) Genetic polymorphisms in organic cation transporter 1 (OCT1) in Chinese and Japanese populations exhibit altered function. $J$ Pharmacol Exp Ther 335:42-50.

Cheng Y, Martinez-Guerrero LJ, Wright SH, Kuester RK, Hooth MJ, and Sipes IG (2011) Characterization of the inhibitory effects of $N$-butylpyridinium chloride and structurally related ionic liquids on organic cation transporters $1 / 2$ and human toxic extrusion transporters $1 / 2-\mathrm{k}$ in vitro and in vivo. Drug Metab Dispos 39 1755-1761.

Dakal TC, Kumar R, and Ramotar D (2017) Structural modeling of human organic cation transporters. Comput Biol Chem 68:153-163.

Egenberger B, Gorboulev V, Keller T, Gorbunov D, Gottlieb N, Geiger D, Mueller TD, and Koepsell H (2012) A substrate binding hinge domain is critical for transportrelated structural changes of organic cation transporter 1. J Biol Chem 287: 31561-31573.

Ermolova N, Madhvani RV, and Kaback HR (2006) Site-directed alkylation of cysteine replacements in the lactose permease of Escherichia coli: helices I, III, VI, and XI. Biochemistry 45:4182-4189.

Gorboulev V, Shatskaya N, Volk C, and Koepsell H (2005) Subtype-specific affinity for corticosterone of rat organic cation transporters rOCT1 and rOCT2 depends on three amino acids within the substrate binding region. Mol Pharmacol 67: $1612-1619$

Gorboulev V, Volk C, Arndt P, Akhoundova A, and Koepsell H (1999) Selectivity of the polyspecific cation transporter rOCT1 is changed by mutation of aspartate 475 to glutamate. Mol Pharmacol 56:1254-1261.

Gorbunov D, Gorboulev V, Shatskaya N, Mueller T, Bamberg E, Friedrich T, and Koepsell $\mathrm{H}$ (2008) High-affinity cation binding to organic cation transporter 1 induces movement of helix 11 and blocks transport after mutations in a modeled interaction domain between two helices. Mol Pharmacol 73:50-61.

Gründemann D, Gorboulev V, Gambaryan S, Veyhl M, and Koepsell H (1994) Drug excretion mediated by a new prototype of polyspecific transporter. Nature 372: $549-552$.

Gründemann D and Koepsell H (1994) Ethidium bromide staining during denaturation with glyoxal for sensitive detection of RNA in agarose gel electrophoresis. Anal Biochem 216:459-461.

Ho SN, Hunt HD, Horton RM, Pullen JK, and Pease LR (1989) Site-directed mutagenesis by overlap extension using the polymerase chain reaction. Gene 77:51-59. Holyoake J and Sansom MSP (2007) Conformational change in an MFS protein: MD simulations of LacY. Structure 15:873-884.

Kaback HR, Dunten R, Frillingos S, Venkatesan P, Kwaw I, Zhang W, and Ermolova N (2007) Site-directed alkylation and the alternating access model for LacY. Proc Natl Acad Sci USA 104:491-494. 
Koepsell H (2011) Substrate recognition and translocation by polyspecific organic cation transporters. Biol Chem 392:95-101.

Koepsell H (2013) The SLC22 family with transporters of organic cations, anions and zwitterions. Mol Aspects Med 34:413-435.

Koepsell H (2015) Role of organic cation transporters in drug-drug interaction. Expert Opin Drug Metab Toxicol 11:1619-1633.

Koepsell H, Lips K, and Volk C (2007) Polyspecific organic cation transporters: structure, function, physiological roles, and biopharmaceutical implications. Pharm Res 24:1227-1251.

Lin L, Yee SW, Kim RB, and Giacomini KM (2015) SLC transporters as therapeutic targets: emerging opportunities. Nat Rev Drug Discov 14:543-560.

Matthaei J, Kuron D, Faltraco F, Knoch T, Dos Santos Pereira JN, Abu Abed M, Prukop T, Brockmöller J, and Tzvetkov MV (2016) OCT1 mediates hepatic uptake of sumatriptan and loss-of-function OCT1 polymorphisms affect sumatriptan pharmacokinetics. Clin Pharmacol Ther 99:633-641.

Minuesa G, Albert C, Pastor-Anglada M, Martinez-Picado J, and Koepsell H (2017) Response to "Tenofovir disoproxil fumarate is not an inhibitor of human organic cation transporter 1". J Pharmacol Exp Ther 360:343-345.

Minuesa G, Volk C, Molina-Arcas M, Gorboulev V, Erkizia I, Arndt P, Clotet B, Pastor-Anglada M, Koepsell H, and Martinez-Picado J (2009) Transport of lamivudine [(-)-beta-L-2', $3^{\prime}$-dideoxy-3'-thiacytidine] and high-affinity interaction of nucleoside reverse transcriptase inhibitors with human organic cation transporters 1, 2, and 3. J Pharmacol Exp Ther 329:252-261.

Nagel G, Volk C, Friedrich T, Ulzheimer JC, Bamberg E, and Koepsell H (1997) A reevaluation of substrate specificity of the rat cation transporter rOCT1.J Biol Chem 272:31953-31956.

Nies AT, Koepsell H, Damme K, and Schwab M (2011) Organic cation transporters (OCTs, MATEs), in vitro and in vivo evidence for the importance in drug therapy. Handb Exp Pharmacol 201:105-167.

Nies AT, Koepsell H, Winter S, Burk O, Klein K, Kerb R, Zanger UM, Keppler D, Schwab M, and Schaeffeler E (2009) Expression of organic cation transporters
OCT1 (SLC22A1) and OCT3 (SLC22A3) is affected by genetic factors and cholestasis in human liver. Hepatology 50:1227-1240.

Pao SS, Paulsen IT, and Saier MH, Jr (1998) Major facilitator superfamily. Microbiol Mol Biol Rev 62:1-34.

Popp C, Gorboulev V, Müller TD, Gorbunov D, Shatskaya N, and Koepsell H (2005) Amino acids critical for substrate affinity of rat organic cation transporter 1 line the substrate binding region in a model derived from the tertiary structure of lactose permease. Mol Pharmacol 67:1600-1611.

Thévenod F, Ciarimboli G, Leistner M, Wolff NA, Lee WK, Schatz I, Keller T, AlMonajjed R, Gorboulev V, and Koepsell H (2013) Substrate- and cell contactdependent inhibitor affinity of human organic cation transporter 2: studies with two classical organic cation substrates and the novel substrate $\mathrm{cd}^{2+} \cdot$ Mol Pharm 10:3045-3056.

Tzvetkov MV, Saadatmand AR, Bokelmann K, Meineke I, Kaiser R, and Brockmöller $\mathrm{J}$ (2012) Effects of OCT1 polymorphisms on the cellular uptake, plasma concentrations and efficacy of the 5-HT(3) antagonists tropisetron and ondansetron. Pharmacogenomics J 12:22-29.

Volk C, Gorboulev V, Budiman T, Nagel G, and Koepsell H (2003) Different affinities of inhibitors to the outwardly and inwardly directed substrate binding site of organic cation transporter 2. Mol Pharmacol 64:1037-1047.

Volk C, Gorboulev V, Kotzsch A, Müller TD, and Koepsell H (2009) Five amino acids in the innermost cavity of the substrate binding cleft of organic cation transporter 1 interact with extracellular and intracellular corticosterone. Mol Pharmacol 76: $275-289$.

Address correspondence to: Hermann Koepsell, Department of Molecular Plant Physiology and Biophysics, Julius-von-Sachs-Institute, Julius-vonSachs-Platz 2, 97082 Würzburg, Germany. E-mail: Hermann@Koepsell.de 